\title{
La villa de "El Saucedo" (Talavera la Nueva, Toledo): Aproximación al estudio de los materiales cerámicos
}

\author{
R. ARRIBAS DOMÍNGUEZ, R. CASTELO RUANO M. BENDALA GALÁN. \\ Dpto. Prehistoria. Universidad Autónoma de Madrid
}

\begin{abstract}
En este estudio se analizan las producciones cerámicas "finas y comunes" aparecidas en las diferentes fases de ocupación constatadas en la villa romana de El Saucedo (Talavera la Nueva, Toledo). Para el período Alto-Imperial (s. I d.C.) y BajoImperial (ss. III-IV d.C) se estudian las producciones más significativas de Terra Sigillata; para las fases más tardías de la ocupación (ss. V-VIII) se analizan las cerámicas comunes de época visigoda.

Palabras clave: Villa; Alto-Imperial ; Bajo-Imperial ; Época visigoda; Producciones Cerámicas.

The "El Saucedo" villa ( Talavera la Nueva, Toledo). An approach to the study of pottery productions

This article analyses the productions of both fine and common pottery found at different archaelogical levels of the Roman villa in AEl Saucedo@ (Talavera la Nueva, Toledo). In the Higher Empire (1st century A.D.) and Lower Empire periods (3th4th centuries A.D.), we study the most significant productions of Galic and Hispanic Terra Sigillata. In the latter settlement phases (5th-8th centuries A.D.), we analyse the common pottery of the Visigothic period.
\end{abstract}

Key words: Roman villa; Higher Empire period; Lower Empire period; Visigothic period; Pottery productions.

\section{1.-INTRODUCCIÓN}

La villa está situada en la finca denominada El Saucedo, junto a Talavera La Nueva (Toledo), muy próxima a Talavera de la Reina, la antigua Caesarobriga y a la vía de comunicación que unía esta ciudad romana con Augusta Emerita. Pertenece al Conventus Emeritensis.

Se han detectado cuatro fases constructivas que se resumen a continuación: A.- Una primera escasamente representada en la que se detecta la estructura de un estanque o piscina de un espacio abierto (Área I) y una serie de muros (Área II) de buena factura a los que se asocian unas instalaciones de fines imprescindibles por el momento, muy arrasadas y amortizadas por la edificación de la segunda fase de la villa. Estas estructuras han sido fechadas a partir de la segunda mitad del siglo I d.C.; B.- A fines del s.III o comienzos del siglo IV, sobre los restos amortizados de la primera, se construyó una típica villa de corte palaciego con una zona fabril; C.- Hacia finales del s. V comienzos del s. VI la gran estancia de planta compleja fue completamente remodelada para convertirla en una basílica cristiana que fue dotada de un baptisterio para el bautismo por inmersión; D.- Tras la destrucción de la villa, al final de la etapa visigoda o a comienzos de la musulmana, siguió una última fase muy mal documentada en la Alta Edad Media que debió de ser una construcción residual y proyectada sólo sobre una parte de las ruinas (Bendala, Castelo y Arribas, e.p.; Castelo, Arribas, López, Panizo y Torrecilla, 1997, 63-98; Castelo, Rodríguez, Panizo y López, e.p.; Ramos Sáinz, 1992; Ramos Sáinz y Castelo Ruano, 1992, 115.137; Ramos Sáinz y Durán Cabello, 1988, 237-243).

Estas cuatro fases constructivas principales se corresponden con otros tantos períodos distintos de ocupación. Definidos por las producciones cerámicas asociadas a cada uno de ellos, en el presente trabajo se propone un acercamiento general al estudio de éstas, relacionándolas con las distintas fases constructivas y sus correspondientes momentos cronológicos.

\section{2.- LAS FASES DE OCUPACIÓN Y LAS PRODUCCIONES CERÁMICAS.}

2.1.- La villa de época Alto-Imperial (fines del s.I, comienzos del s. II d.C)

Poco es lo que se sabe de la primera fase de construcción y ocupación del establecimiento. La gran cantidad de reformas llevadas a cabo sobre este primer plan de la villa han enmascarado y en algunos casos destruido estas primeras estructuras. Construida ex novo, ya que no se han encontrado precedentes ocupacionales prerromanos en el lugar; ha sido mejor documentada en el Área I, donde se encuentran los restos de un estanque de planta cuatrilobulada, perteneciente a un patio o espacio abierto. En el área II, corresponden a esta fase los restos de una serie de muros existentes al sur del gran salón absidado, muy arrasados y amortizados por las sucesivas reformas constructivas, por lo que se hace imposible determinar su planta y finalidad.

Algo más se conoce de esta etapa a través de los hallazgos cerámicos, que si bien de escasa cuantía, en relación con el total recogido, ilustran de buena manera la ocupación del establecimiento a partir de la segunda mitad del s. I y comienzos del s.II d. C. Corresponden éstos a una serie de fragmentos 
adscribibles a buenas producciones de Terra Sigillata Gálica; destacan en especial aquellos que permiten reconstruir al menos tres formas (Ramos Sáinz y Castelo Ruano, 1984, 116). La primera de ellas se trata de una forma Drag. 29 B (Fig.1, núm.1) (S/5527, Corte B1, nivel 3); presenta un gran friso decorativo principal, separado del resto mediante líneas de perlas, en el que se aprecian los clásicos motivos utilizados por los talleres galos: en este caso, grandes guirnaldas y roleos que se desarrollan a lo largo del friso y que cobijan en las zonas que dejan libres a un motivo figurado animal que representa a un perro. Un punzón similar a éste último se documentó en los alfares de La Graufesenque. Según Hermet (1934, 35, Pl. 26), entre las producciones de estos talleres, las representaciones de perros son características del alfarero GERMANUS, en especial durante el denominado "período de esplendor"; sin embargo, en el estado actual de nuestros conocimientos no podemos adscribir con total seguridad nuestra pieza a este alfarero. Por otro lado, las características de la forma, una Drag. 29 B, apuntan a unas fechas avanzadas dentro de las producciones de T.S.G., en concreto a la llamada "Fase de esplendor" o período de máxima perfección técnica, datada entre los años 41 y 60 de nuestra Era, en el que esta forma acentúa sus características morfológicas, siendo la carena más notable y el reborde más saliente, dividiéndose la decoración por medio de festones (Beltrán,1990, 89). Las características tanto formales como decorativas indican unas fechas y origen similares para dicha pieza, aunque la ausencia de marcas de alfar no permite afinar aún más el análisis. La segunda forma reconstruible se trata de un cuenco Drag. 24-25 ó Ritt. 5 (Fig. 1, núm. 2) (S/5528, Corte B1, nivel 3) que, en este caso no presenta decoración. Por último, un tercer fragmento (Fig. 1, núm. 3), de menor tamaño que los anteriores, se corresponde con la
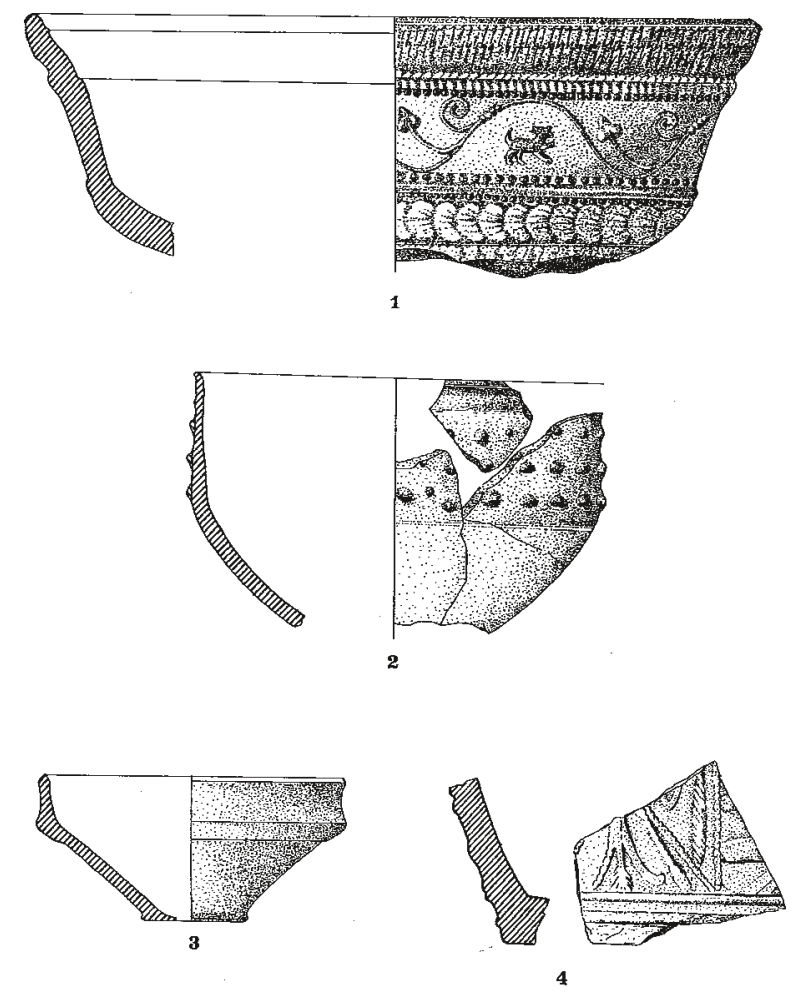

Fig. 1.- Piezas cerámicas procedentes de El Saucedo (Talavera la Nueva, Toledo): 1, 3 y 4.- Terra Sigillata Gálica; 2.- Cerámica de Paredes Finas. carena y friso decorativo principal de una forma Drag. 30 . En este caso sólo se conserva parte de la decoración, consistente en la zona inferior de una cruz de San Andrés, dispuesta entre dos pilastras. Motivos similares aparecen dentro de las producciones de los talleres de la Graufesenque estudiadas por Hermet (1934, 57, Pl. 33), así como en un ejemplar documentado en Conimbriga (Delgado, Mayet y Moutinho de Alarcao, 1975, 79 y 133, núm,. 22), datado en época flavia. Por último, comentar la existencia de otros cuatro fragmentos (semejantes al num. 4 fig. 1.), de menor tamaño, en los que es posible reconocer parte de sus motivos decorativos, consistente en guirnaldas, que en el caso del núm. 6, llenan sus bucles mediante imbricaciones de puntas de flecha. Por otro lado, el fragmento núm. 7 presenta parte de la decoración, consistente en un friso corrido de ovas o lenguetas de las que caen bastoncillos estrellados. Estos motivos son muy comunes dentro de este tipo de producción cerámica, por lo que los paralelos que se pueden citar son amplios. Así , a modo de ejemplo, los motivos decorativos del fragmento núm. 6 presentan similitudes con varios fragmentos recogidos en Baelo Claudia (Bourgeois y Mayet, 1991, 178, núms. 2196, 2197 y 2198), mientras que las ovas o lenguetas presentes en el fragmento núm. 7 , se corresponden entre otros, con ejemplos de este mismo yacimiento (Bourgeois y Mayet, 1991, 177, núms. 45-48).

Las pastas de todos ellos son homogéneas, de buena calidad, con desgrasantes finos y de color rosáceo. El barniz es de tono rojizo, de buena calidad y bien adherido a la superficie del vaso, características propias de las producciones galas.

Por otro lado, el hallazgo de las dos primeras piezas en el Área I, en especial, en los niveles más bajos de la estructura interpretada como estanque o piscina ha permitido fechar la primera fase de esta construcción así como de ocupación de la villa.

Existen más fragmentos de terra sigillata atribuible a talleres gálicos -entre ellos, los cuatro últimos presentados-, dentro de los ejemplares localizados en El Saucedo, a los que sin embargo, no se puede dedicar más espacio en estas páginas. Proceden en su mayoría de un gran conjunto de material cerámico hallado durante las últimas campañas de excavación en una zona situada al sur de la posterior exedra cuadrangular que sirvió de cabecera a el gran salón absidado perteneciente al Área II . En esta zona se llevó a cabo la excavación de una gran fosa -seguramente durante fines del s. IV o principios del s. V d.C.- dedicada a la extracción de arcillas para ser empleadas como material constructivo. Una vez cumplida su finalidad, fue rellenada posteriormente por material constructivo de desecho, formado por guijarros, fragmentos de ladrillos, tegulae, y compactaciones de argamasa. Entre ellos se documentaron numerosos fragmentos cerámicos pertenecientes a diversas cronologías que, en realidad, documentan todas las fases de ocupación de la villa, y a los que se hará referencia a lo largo de este trabajo.

Como se ha indicado la ausencia de marcas de alfarero, así como la generalización del uso de estos motivos decorativos dentro de las producciones galas, no permiten definir los talleres propios de fabricación, aunque debido a las características formales y decorativas que presentan, es muy posible que se trate de producciones salidas de los talleres de La Graufesenque, más activos comercialmente y con mayor presencia en los mercados hispanos interiores, que los talleres de Montans (Beltrán, 1990, 97). Por otro lado, si nos circunscribimos al área geográfica de nuestro yacimiento, el Valle del Tajo, no son muy numerosos los hallazgos de ejemplos de estas producciones. Entre los ejemplos con marca de taller, se pueden mencionar los 
procedentes de "El Balconcillo" Yuncler, Toledo, en donde se atestiguó un sello correspondiente al alfarero gálico FIRMO, que trabajó tanto para los talleres de Montans como para los de la Graufesenque, entre los reinados de Claudio y Domiciano (Pérez González y Juan Tovar, 1984, 145). Un segundo sello correspondiente al alfarero MASCULUS, procede del yacimiento de "La Mezquitilla", en Sonseca. En este caso, se trata de un alfarero de la Graufesenque que firma sus producciones en cronologías sitúadas entre los gobiernos de Claudio y Vespasiano; por último, otra marca, procedente del yacimiento de Santa María, en Noez, que corresponde al alfarero BIO, también perteneciente al centro productor de La Graufesenque fechado en época de Tiberio-Claudio (Pérez González y Juan Tovar, 1984, 146). En este sentido, y como conclusión, se puede decir que los fragmentos de Terra Sigillata Gálica, encontrados en El Saucedo, corresponden en su mayoría a producciones fabricadas en los talleres de La Graufesenque, generalmente en época flavia, el periodo de mayor esplendor y difusión de estos talleres. Estas características coinciden con las pautas generales observadas para este tipo de producciones en las áreas centrales de la Meseta, y en especial en el Valle del Tajo y provincia de Toledo, como ya han puesto de relieve algunos autores (Pérez González y Juan Tovar, 1984, 147).

Por último, y enmarcable también dentro de estas cronologías se dispone de varios fragmentos de mediano tamaño, que permiten reconstruir una forma correspondiente a las conocidas producciones de cerámica de Paredes Finas. Se trata de un vaso de forma Mayet 37 ó 43 (Mayet, 1975, Pl. XLII y LXVIII),

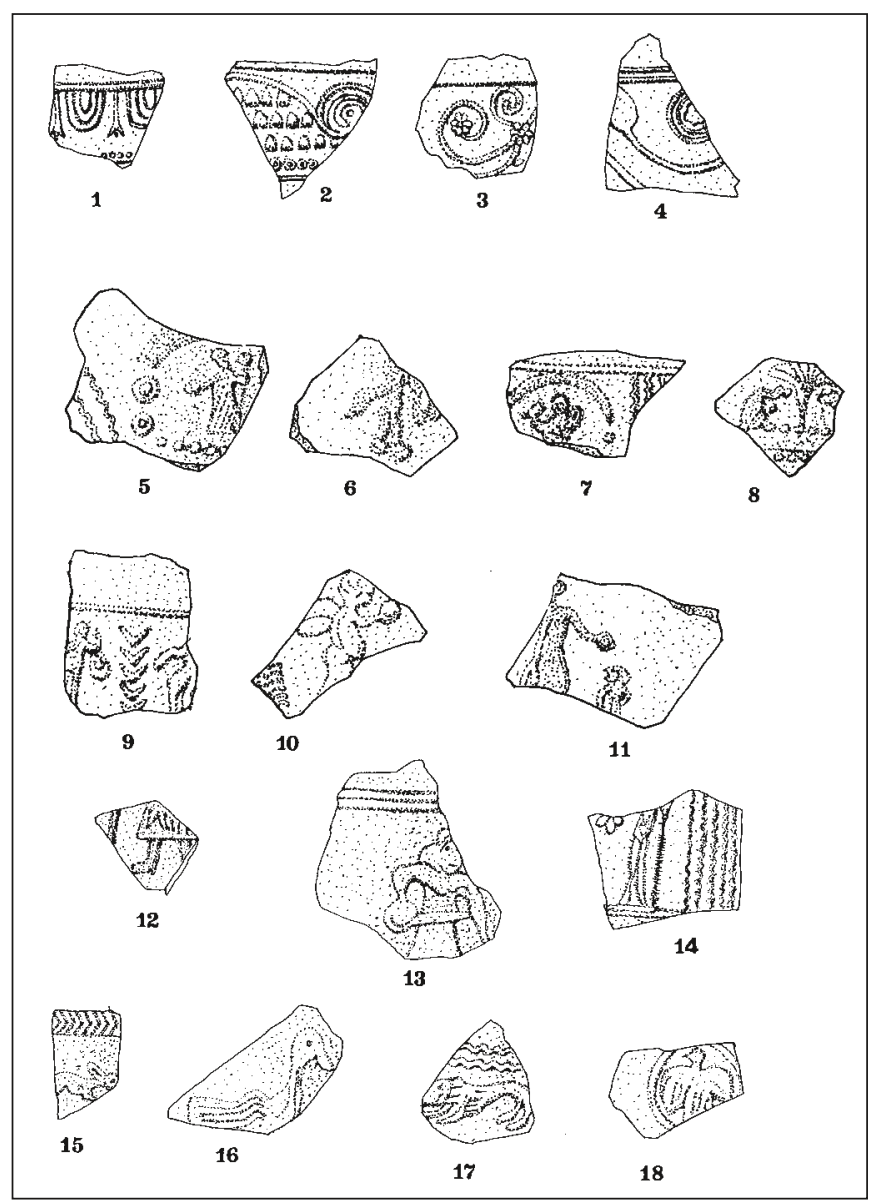

Fig. 2.- Piezas cerámicas procedentes de El Saucedo (Talavera la Nueva, Toledo):1, 2, 3 y 4.- Fragmentos de Terra Sigillata Gálica; 5-18.Fragmentos de Terra Sigillata Alto-Imperial con decoración figurada. que presenta un engobe de tipo arenoso y una decoración a la barbotina mediante perlas ó mamellones de mediano tamaño. Ejemplares similares al nuestro se han documentado en Mérida (Rodríguez Martín, 1996, Fig. 2, núm. 5), uno de los centros de producción de este tipo cerámico, y en dónde según Mayet $(1975,143)$, la forma 43, sería de las más fabricadas (hasta un $60 \%$ de los hallazgos corresponden a esta forma) y con una difusion centrada básicamente en las provincias de Lusitania y Bética, con ejemplares documentados en Conimbriga, Cápara, Torre de Palma, Itálica, Munigua ó Baelo Claudia (Mayet, 1975, 146). En cuanto a la cronología de estas piezas se podría encuadrar entre los gobiernos de Tiberio y Claudio, épocas de mayor actividad de estos talleres (Mayet, 1975, 172).

Bastante más se conoce de las siguientes producciones cerámicas asociadas a esta primera fase de ocupación, que corresponden a la Terra Sigillata Hispánica de época altoimperial. Los hallazgos cerámicos adscribibles a estas producciones y cronologías son el segundo grupo más numeroso -después del formado por las producciones de Terra Sigillata Hispánica Tardía-

Las producciones de Terra Sigillata Hispánica, en su primer grupo o fase altoimperial, aparecen en la Península debido a la instalación en Hispania de diversos talleres, como consecuencia de la popular expansión de las vajillas de mesa tipo Terra Sigillata, a partir del s. I d. C. (Beltrán, 1990, 111 y ss.), perdurando en su producción hasta finales del s. II d.C. (Mezquiriz, 1983, 136). En los comienzos de su fabricación imitan tanto las formas como las decoraciones de los modelos salidos de los alfares galos, pero a partir de época flavia, desplazan a la Terra Sigillata Gálica en todos los mercados hispanos, asistiéndose a la creación de motivos decorativos propios así como de formas típicamente hispánicas. En cuanto a los centros de producción, si bien, existen multitud de pequeñas oficinas a las que últimamente hay que añadir nuevos alfares, hay que resaltar quizá como los dos grandes centros regionales más importantes los de Andújar para la Bética, y los denominados talleres riojanos: Bronchales, Arenzana y Tritium Magallum, en el ámbito de la Meseta norte.

Bien estudiada por numerosos autores (Mezquíriz, 1982; Mayet, 1984; Garabito, 1978, Sotomayor, 1977, entre otros) se encuentra aquí en las definiciones y caracterización de las diferentes producciones atestiguadas de este tipo de cerámica. El propósito de este es, únicamente, presentar los materiales de este tipo aparecidos en el transcurso de nuestras excavaciones en esta villa. El carácter de estudio aproximativo del presente trabajo así como la enorme cantidad de materiales recogido hacen que en estas páginas sólo se refieran a sus características generales así como a recoger algunos ejemplos de los numerosos motivos decorativos utilizados en estas piezas.

En general, dentro de los fragmentos recogidos en la villas, se pueden establecer dos tipos básicos de producciones. Por un lado, se dispone de una gran mayoría de ejemplares que por sus características técnicas y decorativas pertenecen a producciones salidas de talleres riojanos, con los dos grandes centros de Tricio y Bezares; por otro, se dispone de una menor representación de algunas series correspondientes a ciertas producciones del taller de Andújar.

Las producciones atribuidas a los talleres riojanos se caracterizan por poseer pastas depuradas, rosadas de buena calidad y fractura afilada. Los barnices, bien adheridos a la superficie del vaso son de tonos rojizos. En cuanto a las formas, si bien lo fragmentario de los ejemplares no permite reconstruir ninguna forma completa, es abrumadora, al igual que sucede en 
la mayoría de los establecimientos de esta época la presencia de un gran número de bordes pertenecientes a la forma Drag. 29 y 37, sobre todo a esta última. Por lo que respecta a las decoraciones, siguiendo los esquemas decorativos propuestos por Mezquiriz (1982), se pueden observar distintos estilos: el primero y más antiguo es el denominado de imitación gálica, a base de guirnaldas, arquerías, gallones, cruces de San Andrés, etc; inmediatamente después, le sucede el estilo metopado, en el que se aprecian las influencias gálicas observables en los motivos humanos y animales, e incluso algunos vegetales, pero se comienza a advertir la introducción de elementos propios del repertorio hispánico, como los motivos de separación de metopas (líneas onduladas verticales, y líneas de ángulos o bifoliáceas), así como los motivos circulares, que serán a partir del s. II d. C. los característicos y casi exclusivos de la producción hispánica, y que configuran el tercer estilo decorativo o de series de círculos, que pueden aparecer combinados con elementos vegetales $\mathrm{y}$, excepcionalmente, animales o humanos; por último, aunque de presencia algo más escasa, el estilo decorativo de imitación de formas de vidrio, formando un reticulado o facetado, o el de burilado o ruedecilla, que parece ser exclusivo de los talleres de Andújar (Mezquíriz, 1983, 136).

En el caso de los ejemplares hallados en El Saucedo, hay que resaltar la ausencia o escasa presencia del estilo decorativo de imitación gálica, el de cronología más temprana -mediados del s. I d. C, que, como han señalado algunos autores (Garabito et al, 1985, 135) no parece que tuviera una especial difusión y presencia en estas áreas meseteñas del Valle del Tajo.

Predominan dentro del conjunto estudiado, al igual que sucede en otros yacimientos castellano-manchegos, los fragmentos decorados con series de metopas, en las que se representan motivos figurados humanos, animales y vegetales. Este estilo decorativo se utilizó especialmente durante el s. II d.C , el periodo de máxima expansión de los productos riojanos, en los talleres de Tricio y Bezares (Garabito et al, 1985, 135).

En el caso de los fragmentos que se analizan aquí, es abrumadora, la presencia de los motivos de separación de metopas, constituidos en su mayoría por líneas onduladas verticales, y en menor medida por líneas de ángulos o bifoliáceas, siendo común la combinación de ambos motivos (Fig. 3, núms. 1 y 5) como se puede comprobar en los ejemplares recogidos por Garabito (Garabito, 1978, 556 y ss.) en Bezares. Los motivos decorativos alojados en el interior de estas metopas corresponden en su mayoría a punzones figurados, predominando dentro de éstos los relativos a figuraciones humanas y animales, siendo más escasas las de tipo vegetal. La mayoría de ellos son muy utilizados por los alfareros tricienses, como documentan los paralelos identificables entre algunos de los fragmentos de El Saucedo y otros procedentes de estos talleres. Así se puede reconocer en alguno de ellos: las representaciones del mismo tipo de figuraciones humanas, entre las que predomina la representación de Victorias y Fortunas (Fig. 2, núms. 6, 9 y 11), muy estilizadas y a veces, casi irreconocibles, pero de amplia difusión en el ámbito peninsular (Garabito, 1978, 492, 505), pero también figuras de Eros, gladiadores, y otras (Fig. 2, núms.10 y 13). Por otro lado, abundan las representaciones de figuras animales encontrando ejemplos (Fig. 3, núm. 1), con punzones similares a los que presenta otro ejemplar procedente de Tricio, que Garabito y Solovera (1976, 63, núm. 129) interpretan como la representación de una pantera; o también la representación de un águila inscrita en un círculo (Fig. 2, núm. 18) motivo muy frecuente dentro de los talleres de Tritium Magallum (Mayet, 1983, 69, Pl CLXXIX, núms. 1906 y ss.) , o las representaciones de leones ( Fig. 2, núm. 17) entre las que podemos citar como paralelo cercano la procedente de La Alcazaba de Mérida, sobre un vaso Drag. 29 (Mayet, 1983, Pl. CLXXXII, num. 1887); o por último, las difundidas representaciones de conejos y aves (Fig. 2, núms. 15 y 16).

Están igualmente presentes los punzones que representan diseños circulares concéntricos, ya sea ondulados, sogueados o radiados (Fig. 3, núm. 4). En general son de mediano tamaño y buena factura, motivos que serán a partir del s. II d.C. los característicos y casi exclusivos de la producción (Mezquiriz, 1983, 136). La profusión en la utilización de este tipo de figuraciones dentro del estilo decorativo de metopas, así como el posterior reemplazo de estos punzones por los circulares hace encuadrar los fragmentos de El Saucedo dentro de cronologías cercanas a mediados del s. II d. C, momento en el que estos motivos comienzan a ser utilizados masivamente por los alfareros hispanos.

En cuanto al estilo de series de círculos, coetáneo del anterior, aunque preponderante a partir de la segunda mitad del s. II d.C, se dispone de una buena representación dentro de los materiales pertenecientes a la villa, al igual que ocurre en otros yacimientos localizados en torno al cauce del Tajo como el de Santa Cruz de la Zarza (Toledo) (Garabito et al, 1985, 135). Abundan entre éstos, las series de círculos concéntricos, sepa-

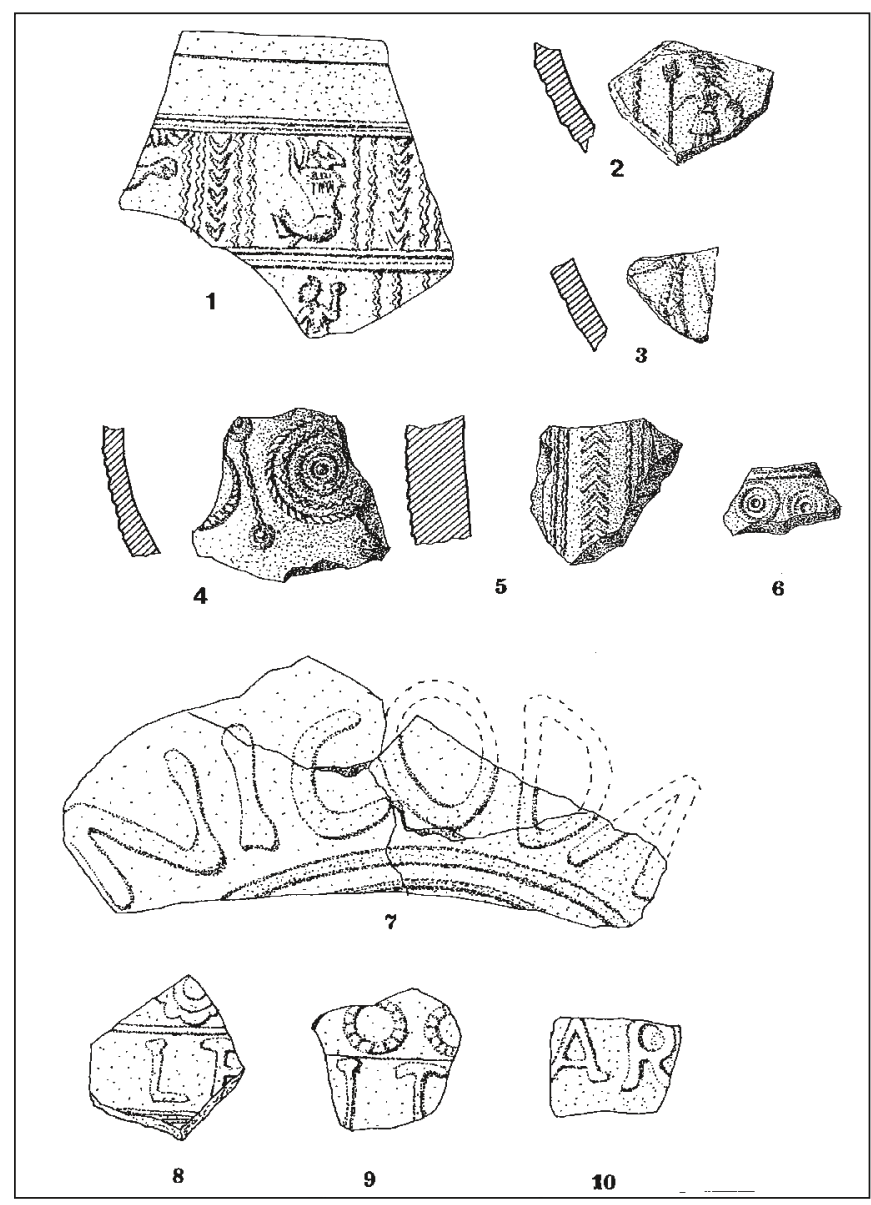

Fig. 3.- Piezas cerámicas procedentes de El Saucedo (Talavera la Nueva, Toledo): 1, 2, y 3.- Fragmentos de Terra Sigillata Hispánica Alto-Imperial con decoración figurada; 4 y 6.- Terra Sigillata Hispánica Alto-Imperial, estilo de círculos; 5.- Idem, motivo de separación de metopas; 7, 8, 9 y 10.- Idem, decoración con letras. 
rados en frisos y alternando generalmente con motivos vegetales o de separacion de metopas. Los círculos se presentan sogueados, ondulados o radiados oscilando en su tamaño así como en el número de anillos.

Otro estilo decorativo representado, aunque en escaso número es el burilado. Esta producción fue atribuida por Mezquíriz $(1983,136)$ casi exclusivamente a los talleres de Andújar, datados desde mediados del s. I hasta mediados del s. II d.C., sin embargo, según Beltrán (1990, 117), estas producciones no rebasarían prácticamente los limites de la Bética, además de la provincia de Ciudad Real (Albadalejo, Mina Diógenes), alcanzando escasamente la Lusitania (Isla de Pessegueiro, Alcácer do Sal y Miróbriga).

Por último, hay que mencionar la existencia dentro del conjunto de materiales estudiados, de una marca de alfarero que, si bien incompleta, puesto que la pieza está fragmentada, habiéndose perdido las primeras letras del sello, conserva la última parte en la que se puede leer: (...)RONTN, marca que puede corresponder a los alfareros FRONTINUS PATERNUS (Garabito, 1978, 132, Fig. 19, núm. 5) , ó C.FRONTONIVS (Garabito, 1978, 458, Fig. 111, núms. 2 y 3). El primero es un alfarero del taller de Bezares, mientras que el segundo procede del de Arenzana de Arriba, en todo caso dentro de la misma área de producción.

Este tipo de producciones procedentes de los alfares de Tritium Magallum, tuvieron mayor difusión peninsular que las de Andújar, especialmente en toda la zona occidental, área cantábrica y en el Valle del Ebro. Como ha señalado Beltrán (1990, 117), fue muy importante el papel de Augusta Emerita como centro redistribuidor de estas producciones, por lo que en este sentido, en los territorios de la actual Comunidad Autónoma de Castilla -La Mancha, se documentan tanto estas producciones como las procedentes de los talleres béticos, aunque están mejor representadas las primeras (Garabito et al, 1995, 134).

En cuanto a las producciones de los talleres de Andújar, están representadas en menor cantidad que las procedentes de los centros riojanos. Aún así, y como ya se ha comentado se dispone de una serie de fragmentos adscribibles a este tipo de taller. Entre ellos, se han seleccionado cuatro ejemplares (Fig. 3, núms. 7, 8, 9 y 10) que remiten a un tipo de producción especial, que presenta como motivos decorativos, composiciones realizadas con letras a molde. Este tipo de decoraciones fue de uso frecuente en los talleres de Andújar (Sotomayor, 1977, Láms. 11 y 12). El primero de ellos conserva gran parte de una inscripción en la que se puede leer NICOD $A$; en el resto de los fragmentos, de menor tamaño, se conservan también varias combinaciones de letras entre las que se pueden reconocer: $L A$ (núm. 8), IT (núm. 9) ó $A R$ (núm. 10). Es también interesante comentar la presencia de dos fragmentos (núms. 8 y 9), en los que las series de letras se combinan con círculos, y que pueden tener sus paralelos, en un ejemplar procedente de Talavera de la Reina y adscrito al centro productor documentado en esta ciudad (Juan Tovar, 1985, 142). Las producciones caracterizadas por estos motivos decorativos, se atribuyen , aunque no con exclusividad, a los talleres de Andújar, en cuyas series se pueden encontrar algunos ejemplos. Así, es común, la representación del sello del alfarero o de la oficina en el exterior del vaso, dentro del campo decorativo, utilizándose también la representación de grandes letras y nombres realizados a molde y de mayor tamaño que los sigilla anteriores, que se convierten casi en los únicos protagonistas de la decoración. Entre los paralelos de este tipo de producciones que se enumeran para los ejemplares documentados en El Saucedo se pueden citar, los depositados en el Museo Provincial de Jaén (Mayet, 1983, 17, Pl. XL, núms. 212-219).

Existen otros centros de producción cerámica además de los ya referidos. Peor conocidos documentan, sin embargo, la extraordinaria difusión de que disfrutó este tipo de cerámica en la Península Ibérica. Entre los que nos atañen más de cerca, se puede mencionar el taller existente en Talavera de la Reina (Toledo), con el punzón nominativo OF CAVINI PR (Juan Tovar et al, 1983), datado entre finales del s. I y la segunda mitad del s.II d.C (Beltrán, 1990, 113), y a cuyas producciones pudieran pertenecer los dos fragmentos comentados anteriormente (Fig. 3, núms. 8 y 9), en los que se combina la decoración de círculos y letras a molde. Sin embargo, por el momento, no se ha encontrado ningún sello similar al de este taller,cuya importancia y difusión son por el momento poco conocidas. ${ }^{1}$

\subsection{La villa de época Bajo-Imperial (fines del III comienzos del IV d.C.).-}

Como ya se ha señalado, tras una primera fase de ocupación en un espacio temporal comprendido entre la segunda mitad del siglo I d.C. y fechas avanzadas e imprecisas del siglo II d.C., se produjo un hiato o una época de muy escasa vitalidad. Tras este periodo, la villa fue reconstruida y reestructurada. Las construcciones de la villa Bajo-Imperial obedecieron a un plan muy distinto, aunque respetaron la orientación de las estructuras de la primera fase de ocupación. Es entonces cuando se configura como una típica villa palaciega con amplias y complejas estancias, zonas termales y demás complementos, además de los espacios y habitaciones destinadas a las labores agrícolas. La villa no se aleja de las características generales de la arquitectura rural documentada en el resto de la Lusitania, caracterizada por presentar: una gran amplitud en las zonas señoriales que llegan a ocupar un alto porcentaje del conjunto total; por la existencia de un conjunto termal en las inmediaciones o dentro de la parte señorial (como en el presente caso) y por presentar una rica decoración musivaria, pinturas murales y elementos decorativos en mármol (Fuentes Domínguez, 1995, 217-237). El Área Fabril estuvo formada por un espacioso patio o corral y un gran ambiente precedido por una zona seguramente porticada y con suelo de tierra batida. El gran ambiente parece configurarse como una gran sala con soportes regularmente repartidos por su interior, que ha sido interpretado como un amplio almacén; porque de tal ha de tratarse a tenor de los materiales que contenía: grandes vasos de almacenamiento; instrumentos agrícolas; cerámica común y de cocina de acabado grosero, restos de animales, escorias, etc. Junto al gran almacén se abre una estancia parcialmente excavada, donde se hallaba una prensa, de la que se ha conservado in situ la gran pieza de piedra que le servía de anclaje. Por dicha habitación discurre una conducción cubierta con lajas de piedra. A través de los instrumentos encontrados tanto en esta área, como en otras de la villa se han podido deducir las siguientes actividades económicas: Agrarias, Ganaderas, Textiles, Forestales, de Carpintería y de Contabilidad y control administrativo de la producción (Aguado Molina, Jiménez Cañizos y Recio Martín, e.p)

En la Zona Señorial se distinguen tres sectores: 1.- Gran salón.- Presenta un espacioso ambiente de compleja planta, en el que se puede apreciar la flexibilidad de las formas arquitectónicas características de este momento de la Antigüedad Tardía que suelen crear formas estilizadas y elegantes (Fernández Galiano, 1992, IV). Las estancias absidadas son 
una señal del lujo aristocrático, reflejo de la ciudad en el campo; aunque comienzan a ponerse de moda a partir del siglo II d.C., no alcanzarán su apogeo hasta el siglo IV d.C. (Alonso Sánchez, 1983, 205). En general la arquitectura es de buena calidad, se aprecia un gran esmero en la terminación de las paredes tal y como puede observarse a través de los enlucidos que debieron de ofrecer una decoración de rico colori$\mathrm{do}^{2}$.

Se conserva buena parte de la decoración exterior del zócalo del muro sureste: una especie de crustae de concepción muy ingenua, formado por líneas que circundan las piedras siguiendo su forma poco regularizada y erizadas después con trazos cortos y radiales del mismo grosor y color. La técnica de juntas de mortero recortadas a modo de cintas decoradas con motivos pintados se ha constatado en otros monumentos; como por ejemplo en la basílica martirial de Marialba (s.IV), próxima a León, en una iglesia de Estambul fechada en el siglo V (Hauschild, 1968, 244 y 248 y 1982, 78 y 1970, 514); Sta. María de Melque (Caballero Zoreda, 1980) y en los Hitos (Toledo) y en el Castillo de Gormaz, Soria (Caballero en Hauschild, 1982, 85). Esta misma técnica de juntas encintadas y realzadas cuidadosamente también se ha constatado en León (García y Bellido, 1970,572).

El suelo se cubrió con una sencilla pero efectista y bien cuidada alfombra de mosaico geométrico que ocupa una superficie aproximada de 97 metros cuadrados. Se puede comprobar, tal y como señala Guardia Pons para otros yacimientos, que la sala principal (de recepción o aparato) de dimensiones considerables presenta un estudiado sistema de ordenación de los temas decorativos representado en los pavimentos, de tal forma que en los dos pasillos absidados, las composiciones geométricas elegidas (círculos secantes y octógonos alternando con cuadrados) enfatizan su función de paso (Guardia Pons, 1992, 416).

En el centro de esta habitación se documentó una plaqueta sumidero que comunicaba con una alcantarilla de drenaje, dicha plaqueta estuvo incluida en el primer planteamiento de la sala como demuestra el marco negro de mosaico en que se inscribía y la inclinación del pavimento. El tapiz central está integrado por una composición ortogonal de octógonos irregulares y cruces latinas adyacentes que forman hexágonos oblongos.

Los dos pasillos absidados de la pared noroeste presentan pavimentos musivarios distintos. Uno de ellos tiene una composición ortogonal de círculos secantes que dejan entrever cuatripétalos y en la zona absidada dos delfines con las colas enlazadas y enroscadas a un tridente. El otro se caracteriza por tener una composición ortogonal de octógonos y cuadrados y en el ábside una copa de la que emergen roleos. 2.- Zona termal.- Parcialmente excavada, ha sido posible documentar los restos de cuatro ambientes: Apodyterium, Frigidarium, Tepidarium y Caldarium, que configuran un conjunto balnear o termal de carácter privado que daría servicio al dominus y su familia. Estudiado ya , monográficamente, no se abunda aquí en su descripción y análisis (Bendala, Castelo y Arribas, e.p.; Arribas, e.p. y Torrecilla Aznar, e.p.) 3.- Pabellón Cuatrilobulado.- Se encuentra situado cerca de la zona fabril. Apenas se puede decir nada de él ya que fue sacado a la luz antes de las intervenciones arqueológicas de 1982 y por tanto no se dispone de documentación sobre las circunstancias de su hallazgo. Está formado por una planta cuadrangular que presenta en cada uno de sus lados una sala rectangular rematada en dos ábsides: de estas cuatro salas solo se conservan dos. La planta cuadrangular central esta pavimentada con una estrella de ocho puntas obtenida a través de la unión de dos cuadrados en lacería de trenzas acantonada con rombos. Una de las dos salas de planta rectangular rematada en ábsides presenta en la zona rectangular una composición de círculos, cuadrados y rectángulos rectilíneos o carretes y en los ábsides pavos reales frontales con las colas explayadas. El otro ambiente conservado presenta, en la zona rectangular, una composición de hexágonos escutiformes cruzados, dejando entrever octógonos; cuadrados y rombos y en los ábsides composición de peltas y círculos secantes formando tetrapétalas que cobijan hojas de hiedra (Castelo et alii, e.p).

Los mosaicos de El Saucedo no se alejan de los pavimentos documentados en otros latifundios del valle del Tajo, Duero o Ebro que se cubren con extensas alfombras musivas. En todo este ámbito Mérida juega un papel fundamental como impulsor y difusor de estos talleres (Ramallo Asensio, 1990, 162). Se determina que, en el caso de los mosaicos documentados en la villa de El Saucedo, se emplearon composiciones repartidas prácticamente por todas las partes del Imperio. El programa ornamental observado en la Pars Urbana, concretamente en los pavimentos musivarios, debió estar completado por la presencia de escultura arquitectónica y plástica de la que lamentablemente, al menos por el momento, no existen demasiados testimonios. Podemos mencionar un pie calzado de mármol, una pezuña de pata de caballo y algunas esculturas (un togado y una Venus) halladas en el siglo XVII por el historiador de Talavera P. Ajofrin (Fita, 1882, 234).

En cuanto a la cerámica, las producciones de Terra Sigillata Hispánica son sustituidas a partir de fines del s. III d.C., por un nuevo tipo cerámico, la llamada Terra Sigillata Hispánica Tardía (TSHT). Si bien en los últimos años, el estudio y la investigación de estas producciones ha registrado un extraordinario auge, tanto en la calidad como en la cantidad de trabajos que ha generado (Mezquiriz, 1961; Palol, 1974; Mezquiriz, 1983; V.V.A.A., 1983; Mayet, 1984; López Rodríguez, 1985; Carrobles y Rodríguez Montero, 1988; Pérez Martín, 1989 y Paz Peralta, 1991, entre otros), quedan aún algunas lagunas o problemas en su conocimiento, en especial, los relativos a su origen, relación con las producciones anteriores, centros de producción, y vías de comercialización y distribución (Mezquíriz, 1983, 136).

Se trata de un tipo de producciones con caracteristicas propias, aunque con numerosas reminiscencias de las producciones anteriores, típicas de los s. IV y V.d. C. Como ya se ha indicado, se desconoce su origen, así como las producciones correspondientes al s. III d.C, ya que la TSHT, parece ser que aparece perfectamente formada en el s. IV d.C, puesto que en los estratos pertenecientes a momentos anteriores, está claramente ausente. Para Mezquíriz, se trataría de unas producciones fabricadas en pequeños alfares que sobreviven al hundimiento de los grandes centros de producción, constituyéndose como una especie de industria de pequeños artesanos, que continúan fabricando una serie de formas que perduran y que suplieron la inexistencia de los grandes centros de producción que aparecen en la Meseta a partir del s. III d.C. (Mezquíriz, 1983, 136).

En cuanto a las formas, si bien aparecen tipos nuevos, propios de esta producción en particular, definidos entre otros por Mezquíriz (1963, 1983), la forma más difundida y que aparece en mayor cantidad es la denominada 37 Tardía, ya que suele constituir un $80 \%$ del total de formas analizadas en los disitintos yacimientos. Esta forma se caracteriza por presentar un perfil curvo con borde de tendencia saliente, en forma de embudo, cuyo labio suele presentarse engrosado, y un pie 
muy bajo o en la mayoría de los casos inexistente. Generalmente es la forma predominante dentro de las producciones decoradas a molde, disponiédose la decoración en el cuerpo, nunca en el cuello o borde (Mezquiriz, 1961, 84-85; López Rodríguez, 1985, 19; Carrobles y Rodriguez, 1988, 30).

En cuanto a los estilos y motivos decorativos que se documentan en estas producciones se ha producido a lo largo de los últimos años, una serie de tipologías o diferenciaciones en estilos. Aunque, la clasificación propuesta por López Rodriguez (1985), parece ser la más estructurada y aceptada, es necesario comentar que desde un punto de vista general, tienen todavía validez las clasificaciones propuestas por Mezquiriz (1983) y Mayet (1984) entre otros. En este sentido, se podrían definir tres estilos decorativos principales; así, en un primer momento, perduran los motivos empleados en las producciones anteriores: series de círculos, rosetas, y elementos vegetales, siendo muy escasas las representaciones humanas y animales, realizadas con una factura tosca y grueso relieve. En segundo lugar, otro estilo que presenta motivos estampados. Por último, aparece el estilo más empleado y peculiar de este tipo de producciones, en el que se representan grandes círculos rellenados por series de ángulos, baquetones y otros motivos. Para Mezquíriz (1983, 136), este nuevo tipo decorativo obedeceria a esquemas y tradiciones diferentes a las presentes en la Terra Sigillata Hispánica Alto-Imperial.

Los fragmentos cerámicos pertenecientes a estas producciones procedentes de la villa de "El Saucedo", forman el conjunto más amplio dentro del total cerámico recogido. Este es un hecho común a la mayoría de los establecimientos hispanorro-

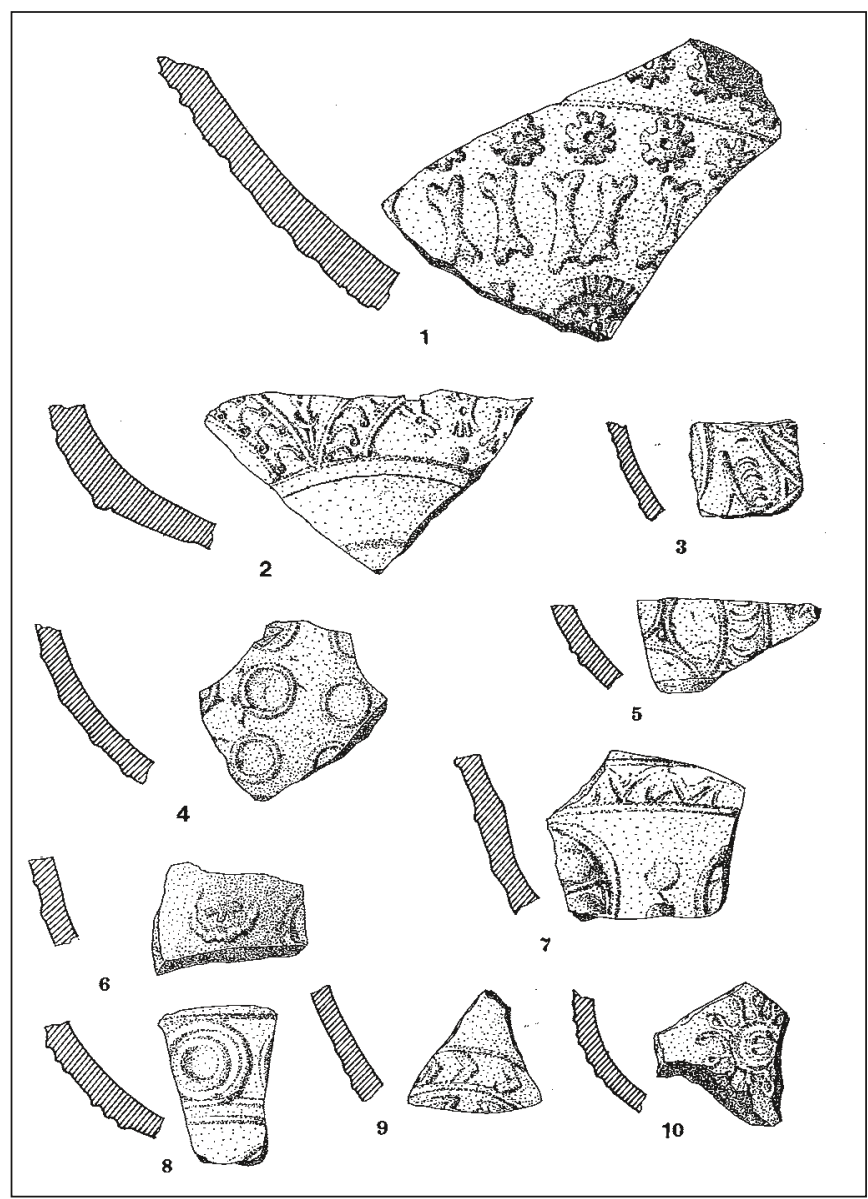

Fig. 4.- Piezas cerámicas procedentes de El Saucedo (Talavera la Nueva, Toledo): 1-10.- Terra Sigillata Hispánica Tardía. manos tipo villa, algo lógico, ya que la T.S.H.T. representa el tipo de cerámica usada en las fases de ocupación más largas, y en las que estos complejos llegan a su máximo esplendor: las correspondientes a los s. III a V d. C. En los ejemplos que presentamos (Fig. 4, núms. 1-10), se encuentran bien representados los estilos decorativos de que hemos hablado: rosetas y series de círculos concéntricos (Fig. 4, núms. 6 y 8), grandes círculos rellenos de series de ángulos y (Fig. 4, núms. 2, 3, 5, 7 y 9) o series de rosetas alternando con series de bastones y círculos con rosetas inscritas (Fig. 4, núm. 1). Este último ejemplo en particular, dispone de paralelos similares entre los materiales recogidos durante los trabajos en el solar del nuevo Mercado de Abastos en Toledo ( Carrobles y Rodríguez Montero, 1988, 169 y ss), en concreto, las rosetas utilizadas son similares al tipo 1B - roseta simple sin orificio central-de Carrobles y Rodríguez (1988, 32), las más utilizadas en este tipo de producciones. Por último hay que hacer mención a la existencia dentro del material de El Saucedo de fragmentos con una decoración característica, con motivos vegetales estampados y que se corresponderían con el segundo estilo decorativo propuesto por Mezquíriz (1958).

\section{3.- La basílica cristiana (fines del siglo V-VI d.C.)}

A fines del siglo V comienzos del VI se produce una importante reforma de las edificaciones existentes: el gran salón de compleja planta antes descrito fue remodelado para convertirlo en basílica de culto cristiano. Esta basílica continuó perteneciendo a la Lusitania, al Conventus jurídico Emeritensis y debió tener como sede episcopal Salmantica. ${ }^{3}$. Es posible que la edificación de la basílica estuviera relacionada con la intención de cristianizar un lugar ya sagrado en época prerromana y romana, lugar donde debió desarrollarse un culto a las ninfas ya que se tienen noticias del hallazgo de un ara votiva dedicada a estas divinidades (Fita, 1882, 234).

Las últimas campañas han permitido comprobar que la reforma se hizo sobre la base de una construcción prácticamente desmontada, que podía estar más o menos arruinada, o fue derruida intencionadamente para proceder a la gran reforma programada; el hecho es que los muros quedaron eliminados hasta unos $50 \mathrm{~cm}$. de altura.

El resultado fue la obtención de una basílica de planta rectangular de $8 \times 15 \mathrm{~m}$. de superficie con cabecera cuadrangular de $3 \times 2{ }^{\prime} 5 \mathrm{~m}$. y orientada de oeste a este. La entrada pudo efectuarse por los pies, donde los restos constructivos sugieren la posibilidad de la existencia de una disposición en atrio circunscrito por los dos pasillos absidados que a partir de ahora denominaremos como paraclesia, aunque esta zona está muy destruida y es imposible precisar detalles formales. No parece, por otra parte, que hubiera un espacio equivalente a un nartex y tan solo se dispondría de la gran sala sin división en naves (Ramos Sáinz y Castelo Ruano, 1992, 115-137). La cabecera es de planta rectangular (3 x 2’5 m.). Cerrillo Martín (Cáceres) cree que serían los alrededores de Mérida la zona geográfica en la que por primera vez se implantaron las cabeceras cuadrangulares a las que considera de influencia oriental procedente desde las costas sirias hasta el Adriático (Cerrillo Martín de Cáceres, 1981, 233, 241,242). Esta influencia del Mediterráneo oriental que se detecta en la forma de la cabecera coincidiría con la que presenta el pavimento que se colocó en ella. El mosaico fue arrancado antes de nuestras excavaciones y se encuentra depositado en el Museo de Santa Cruz de Toledo desde 1981. Gracias a la amabilidad del Director del Museo de 
Santa Cruz de Toledo: D. Rafael García Serrano se pudo analizar el pavimento detalladamente. En él se representaron varias bandas ornamentales que encierran un medallón en el que se figura un busto femenino ataviado con túnica y manto que portaba cornucopia y globo, acompañada por la inscripción ISCALLIS.

Se interpreta esta representación como la personificación de Thyché o Fortuna, en esta ocasión acompañada por dos de sus muchos atributos: la cornucopia y el globo, tal y como aparece representada en algunas monedas recogidas en el Lexicon Iconographicum Mythologiae Classicae (vol. VIII.1, 131 y vol. VIII.2, 98, n1 89, 91 y 94).

Es este busto una representación única en esta parte de Europa occidental en una época tan tardía, pues la mayoría de los talleres musivarios no se encontrarían ya capacitados para realizar tales representaciones, que entrañaban un alto grado de dificultad.

Podría pensarse que este mosaico, al igual que señala Palol para los mosaicos cristianos de las Baleares, estuviera relacionado con un renacimiento musivario de tiempos bizantinos, mosaicos que son completamente distintos a lo peninsular y ejecutados en un momento en que en la Península Ibérica es probable que haya desaparecido del todo la tradición del mosaico romano (Palol 1967). Por otro lado, la iglesia se dotó de una piscina bautismal situada en el interior de un recinto de planta cuadrangular, no excavado en su totalidad. Es de tipo cruciforme de brazos iguales (Ramos Sáinz, 1992). La presen-

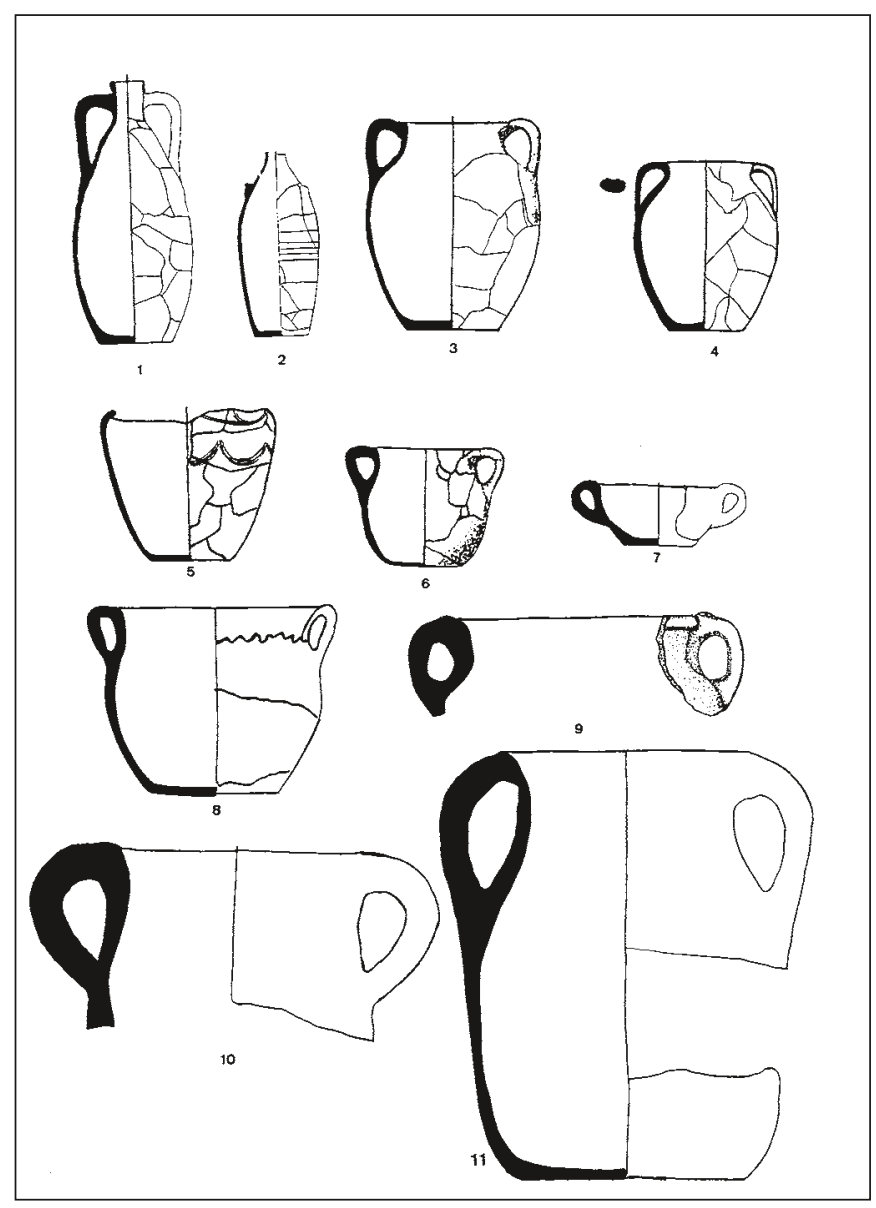

Fig. 5.- Piezas cerámicas procedentes de El Saucedo (Talavera la Nueva, Toledo): 1 y 2.- Botellas de dos asas; 3, 4, 6, 8, 9, 10 y 11.Ollas con dos asas de borde vuelto hacia afuera; 5.- Olla con borde vuelto hacia adentro y 7.- Cuenco con dos asas. cia de un baptisterio entre el mobiliario litúrgico es un denominador común de las iglesias de la Lusitania tal y como se puede apreciar en La Cocosa, Casa Herrera y San Pedro de Mérida (Badajoz) y en El Gatillo de Arriba y Alconetar (Cáceres). La instalación de baptisterios en el ámbito rural parece ser un fenómeno avanzado que parece situarse en el siglo VI al menos para el Conventus Emeritensis y en el Pacensis (Gurt Esparraguera, 1995, 78). Hubo otras reformas que completaron el cuadro de la importante remodelación del lugar para su conversión en basílica Los muros perimetrales de la basílica de El Saucedo pudieron haber tenido una altura escasa y debieron de estar terminados en tapial. La cubierta pudo ser de armazón de madera tanto para la nave como para el santuario debido a la numerosa presencia de clavos de diferente tamaño y sección. El resultado exterior sería a dos vertientes a base de tegulae e ímbrices. La cubierta del santuario pudo tener un nivel inferior a la de la nave con el fin de acentuar los volúmenes desde el exterior y permitir la presencia de algún vano a modo de iluminación. Mientras la basílica estuvo en uso se registraron reformas de menor cuantía,obras que empobrecen la prestancia arquitectónica heredada de la villa originaria y mantenida en lo esencial en la remodelación. Fuera de contexto y hallado de forma casual se documentó el altar realizado en gneis (Ramos Sáinz y Castelo Ruano, 1992).

La aparición de parroquias rurales es un fenómeno bien documentado, no sólo en la Lusitania sino también en el resto

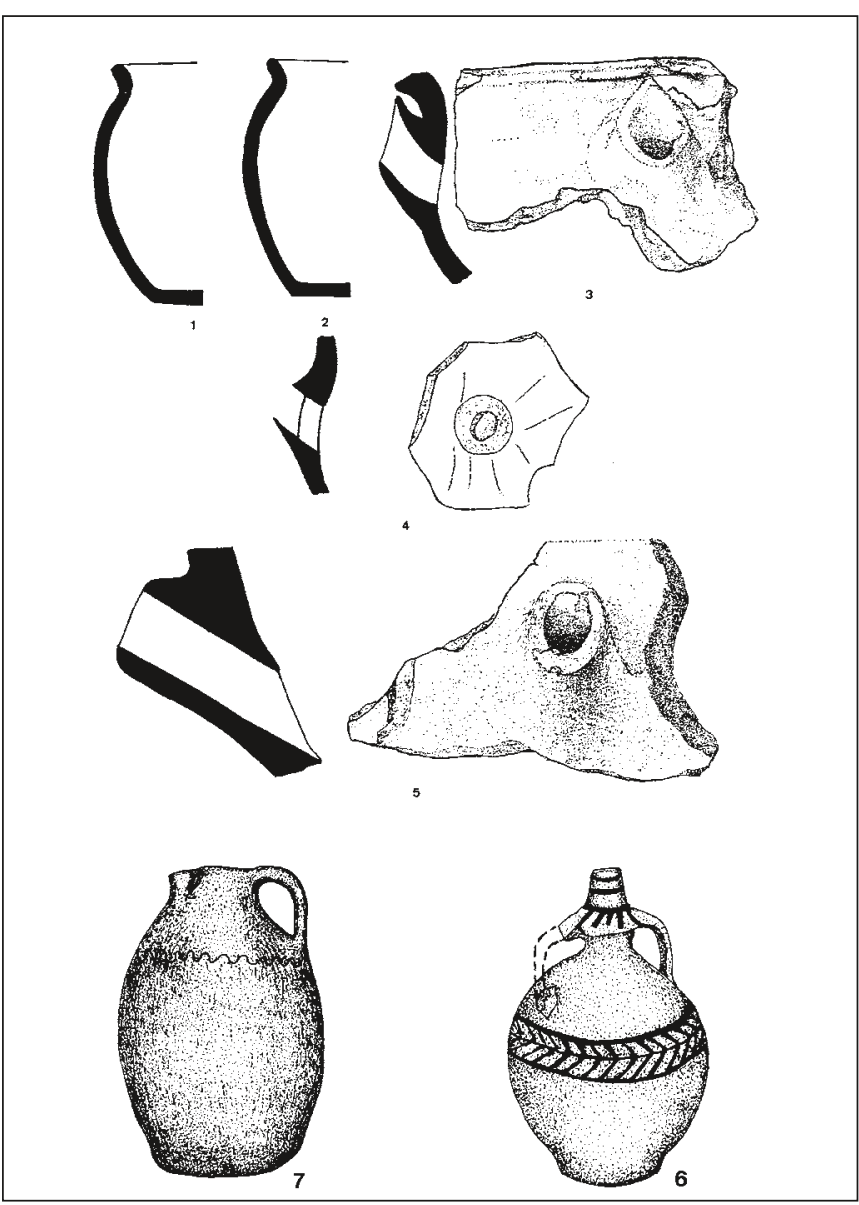

Fig. 6.- Piezas cerámicas procedentes de El Saucedo (Talavera la Nueva, Toldeo): 1 y 2.- Ollas sin asas con el borde vuelto hacia afuera; 3-5.- Cuencos con pitorro; 6.- Jarra de cuello moldurado y engrosado y 7.- Jarra de boca trilobulada. 
de Hispania. Su presencia constituye una verdadera colonización del territorio con un doble sentido de cristianización y establecimiento de un dominio territorial de carácter eclesiástico por parte de la sede episcopal y además servirán para aglutinar a las comunidades rurales cristianizadas (Gurt Esparraguera et alii, 1994, 179 y Gurt Esparraguera, 1995, 90). La basílica de El Saucedo pudo tratarse como ha sugerido Cerrillo Martín (Cáceres) para la iglesia de Ibahernando de un pequeño edificio de función cultual-parroquial con carácter privado; parroquial desde el punto de vista que supone la atención religiosa de una pequeña comunidad y privado por hallarse en una villa rural.

Cuando parte de la villa fue reutilizada como basílica, continuó en uso la explotación agropecuaria, circunstancia que no sólo se puede comprobar por las reformas arquitectónicas detectadas en la antigua zona doméstica si no también por los hallazgos de cerámica común que ofrecen una cronología avanzada de finales del siglo $\mathrm{V}$ y comienzos del VIII d.C.

Se ha de hacer constar que la cerámica común está practicamente por estudiar de una manera global. Su abundancia, fragmentariedad y circunstancias concretas de producción han hecho que se considerara su estudio como una tarea poco menos que imposible (Fuentes Domínguez, 1989, 216). No obstante hay que mencionar el estudio general, ya clásico, publicado en 1973 por M. Vegas quien dividió la cerámica común romana en cuatro grupos según su funcionalidad:

a) vasijas de cocina: empleadas para cocinar, para la preparación de alimentos y para lavar. Son utensilios simples y prácticos conocidos genericamente con el nombre de Vasa coquina(to)ria. Para cocer se emplearon ollas y cuencos (aula) olla, coccabus, cortina, lebes, tripes), para freír (bridum, frixorium y patina) y como instrumentos auxiliares para la preparación de alimentos: morteros, coladores, embudos, etc.

b) vasijas de mesa: en este grupo se incluyen los utensilios para beber Vasa potoria (vasos, jarras de agua y vino, vasijas para mezcalr vino y agua, coladores, cucharones para servir la bebida).

c) vasijas para guardar provisiones tanto líquidos como sólidos (vino, aceite, salsas, cereales, fruta, etc.).

d) vasijas de tocador : pequeños tarros para guardar perfumes y ungüentos (Vegas, 1973, 7 y 8).

La cerámica documentada para esta etapa tardía se finales del siglo V al VIII se caracteriza, en líneas generales, por presentar las superficies rugosas al tacto y las paredes exteriores pueden estar simplemente alisadas o bien presentar ondulaciones o estrias profundamente marcadas en el torno o hechas a peine. Estas cerámicas, como más tarde se especificará, suelen reproducir formalmente tipos tradicionales del Alto y Bajo Imperio pero con unas características técnicas y algunas innovaciones formales que permiten individualizarlas con respecto a los modelos anteriores. Las cerámicas Tardo-Imperiales de época visigoda se caracterizarán por presentar como característica la uniformidad de tipos a pesar de la diversidad de detalles en las formas concretas que las hacen distíntas (Fernández Gómez et alii, 1984, 355-378).

Se han planteado problemas en torno a la cerámica de este periodo tan tardío, entre ellos el de la terminología que debe emplearse para su estudio. Han sido muchos los investigadores que han utilizado el término de "cerámicas visigodas" para referirse a estas producciones artesanales; sin embargo autores como Izquierdo Benito, Lucas Pellicer y Fernández Gómez consideran que este nombre no se puede basar en el solo hecho de que su producción coincida con la llegada y asentamiento de los pueblos germánicos en la Península ya que parecería implicar una superioridad germánica que historicamente no puede probarse. Se ha llegado a la conclusión de que hay que hablar de cerámica hispanorromana o de época visigoda ya que ésta se fabricaría por manos alfareras y en talleres hispanorromanos con formas, que como ya se ha señalado anteriormente, se venían utilizando en la península e incluso estaban enraizadas con elementos indígenas y romanos. Por tanto el pueblo godo no aportaría ni manos ni formas originales si no que imitaría éstas y utilizaría aquellas (Fernández Gómez et alii, 1987).

En el caso de El Saucedo se documentan ejemplares cerámicos pertenecientes a la Vajilla de cocina : ollas con borde vuelto hacia afuera (con asas): núms. de inventario: S / 4003, Nivel 1, A4; S/23033, Nivel 2, H4; S/4064 y S/4060, Nivel 2, A4; S/23027, Nivel 1, H4; S/23037 y 23038, Nivel 2, H4, y sin número de inventario, Nivel 2, H2 (Fig. 5, núms. 3, 4, 6, 8, 9, 10 y 11); ollas con borde vuelto hacia afuera ( $\sin$ asas): S/ 23036 y 23035, Nivel 2, H4 (Fig. 6, núms. 1 y 2); cuencos con dos asas: S/23034, H4, Nivel 2 (Fig. 5, núm. 7); cuencos con pitorro: S/5150, Nivel 1, B1; S/17018 Nivel superficial, O1 y S/2108, Nivel 2, A2 (Fig. 6, núms. 3, 4 y 5); y a la vajilla de mesa, entre las que se han documentado:Jarras de cuello moldurado y engrosado, como los ejemplares recogidos en las prospecciones de Martín Aguado y otro sin número de inventario procedente del Nivel 2 del Corte O2 (Fig. 6, núm. 6); botellas de dos asas como las núms. S/4017, del Nivel 1, A4 y S/23032, del

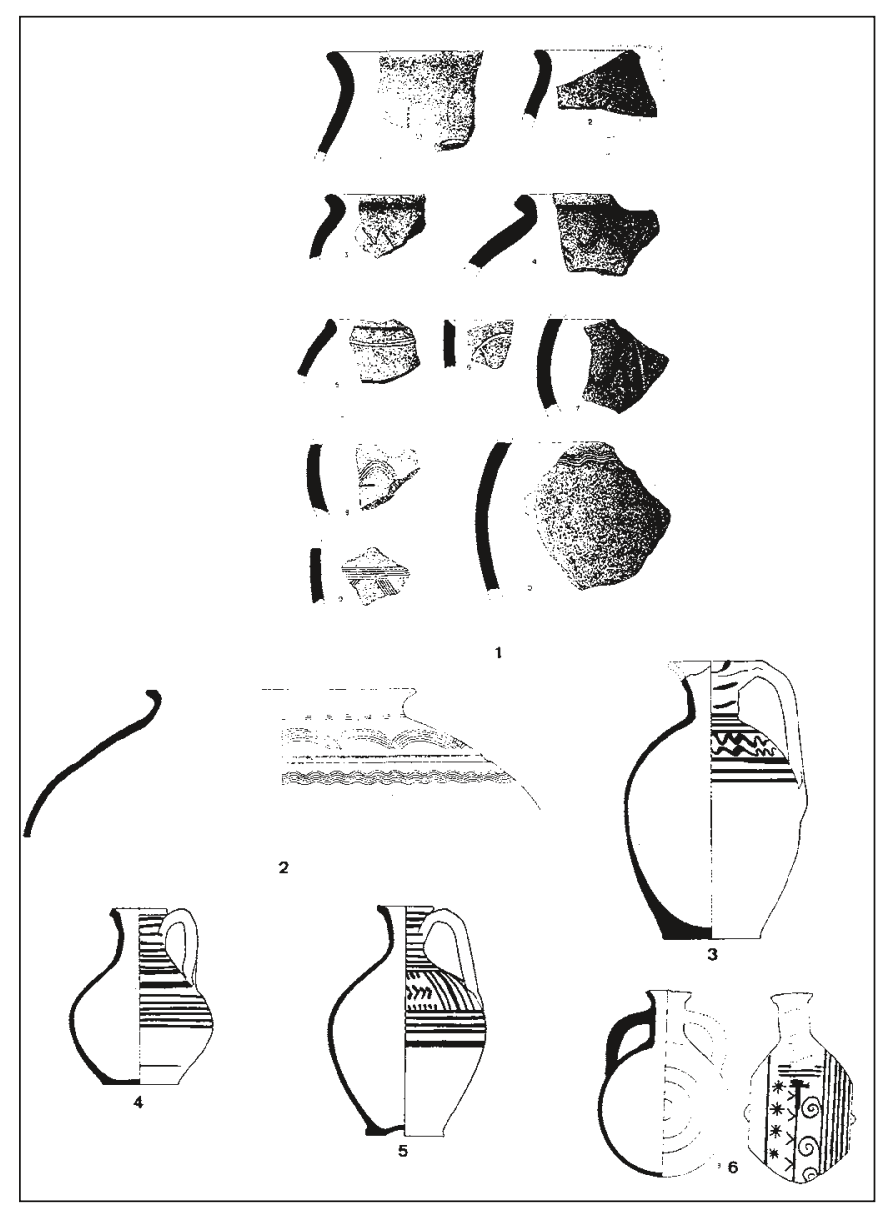

Fig. 7.- Piezas cerámicas con decoraciones incisas a peine: 1.- Ollas de borde vuelto hacia afuera y hacia adentro procedentes de El Germo (Córdoba; según Ulbert); 2.- Olla con borde vuelto hacia afuera. Cueva de Suano (Santander; según Bohigas y Roldán y Ruíz Gutierrez, 1989). Piezas cerámicas con decoración pintada: 3-6 San Miguel de Arroyo (Valladolid; según Palol, 1969). 
Nivel 2, H4 (Fig. 5, núms. 1 y 2) así como jarras de boca trilobulada, como la procedente del testigo existente entre los cortes H3 y H2 (Fig. 6, núm. 7).

Las decoraciones documentadas en las piezas del citado yacimiento consisten en: 1.- incisiones simples (olla de borde vuelto hacia afuera con dos asas, jarra de boca trilobulada); 2.- incisiones múltiples onduladas o quebradas (olla de borde vuelto hacia afuera con dos asas y olla de borde vuelto hacia adentro). En general, éstas son poco profundas y presentan un trazo fino, siendo realizadas a peine. Se presentan en grupos de cuatro incisiones paralelas muy juntas y no son extrañas en los ambientes de época tardorromana y visigoda. Entre los numerosos ejemplares constatados destacan los recogidos en la Fi.7, nums, 1-2 3.- incisiones profundas (botellas de dos asas), consisten en incisiones paralelas algo separadas y profundas lo que hace que el espacio comprendido entre ellas quede como en resalte, a modo de molduras. Se desarrollan siempre en la panza. Ejemplares semejantes se encontraron en San Pedro de Alcántara (Málaga). 4.- motivos pintados (jarros de cuello engrosado y moldurado), con respecto a éstas decoraciones Izquierdo Benito y Fernández Gómez consideran que los motivos decorativos representados son de tradición antigua y enlazan con lo romano. Cree que de ninguna manera pueden paralelizarse con los representados en las cerámicas árabes (Fernández Gómez et alli, 1987,196). La cerámica común pintada representa por sí sola un mundo amplísimo dentro del conjunto de las cerámicas romanas. Aunque existen producciones del siglo I d.C. en las que la barrera con el material indígena es más dificil de establecer, lo cierto es que su desarrollo comienza a mediados del siglo II y su apogeo va a darse en el siglo IV d.C. (Abascal Palazón, 1984, 49 y 52). El mundo Tardorromano conoció un gran auge en las producciones pintadas lo que no significa que en el Bajo Imperio el impacto de la cerámica pintada haya sido más importante que en el siglo I d.C. pero lo que si se puede afirmar es que los materiales antiguos son muy abundantes y uniformes, al contrario de lo que ocurre con los materiales tardíos en las que las tipologías y varientes, seguramente debidos a los múltiples talleres locales, son muy numerosos (Abascal Palazón, 1984, 49 y ss.). Al ser frecuente la presencia de vasijas con decoración pictórica en contextos funerarios, Fernández Gómez, planteó la posibilidad de que éstas decoraciones no sólo fueran un simple elemento decorativo $\mathrm{u}$ ornamental si no que pudieran tener un significado ritual. Recipientes con decoración pintada semejante a la documentada en las piezas de El Saucedo se han hallado en las necrópolis indicadas en la Fig, 7 nums 3-6. Todos los tipos decorativos documentados se distribuyen como en la mayoría de las piezas de época visigoda, en la parte alta y media del vaso.

\section{I.- Vasijas de cocina}

a) Ollas con borde vuelto hacia afuera.- Deben incluirse dentro del Grupo I de Vegas y forma 5 de Izquierdo Benito.( Fig 7, nums 1-5) Constituyen sin duda alguna, la forma más característica de la cerámica común en el mundo romano por lo que presenta problemas a la hora de realizar precisiones geográficas y cronologicas. Presentan un fondo plano y por lo general tienen un cuerpo piriforme o globular. A menudo tienen un corto cuello y pueden poseer dos asas. se documentan en todas las provincias del Imperio durante toda la época romana. Las cerámicas del grupo I de Vegas comienzan su desarrollo a partir del siglo II a.C. pero es indudable que per- viven manteniendo, mas o menos, sus rasgos hasta época Bajo Imperial, entrando algunas formas en la Edad Media (Argente Oliver, 1979,73). Para Gamo Parras es posible que las ollas con dos asas deriven de prototipos de cerámica africana de cocina (Gamo Parras, 1996,365). En la fase Bajo-Imperial estas ollas carecen, muy a menudo de cuello y sus paredes suelen estar decoradas con grupos de finas estrias o bien presentar una superficie ligeramente ondulada, además los ejemplares de época tardía tienen a menudo dos asas tal y como se puede apreciar en alguno de los ejemplares del yacimiento que tratamos (Vegas, 1973,11).

b) Ollas con borde vuelto hacia adentro.- Se incluyen en el grupo 3 de Vegas (Fig. 8, núms. 8 -14). Se caracterizan por presentar un cuerpo globular y sin transición de cuello que se inclina más o menos profundamente hacia adentro terminando con bordes lisos o engrosados. Se trata de un tipo de olla que deriva de formas de la época de La Tené y que con diversas variantes se encuentra en diferentes provincias del Imperio durante toda la época romana. Presenta pues, este tipo, una cronología muy amplia ya que existen formas que deben considerarse como una supervivencia de las cerámicas indígenas de las distintas regiones. Esta forma está documentada en

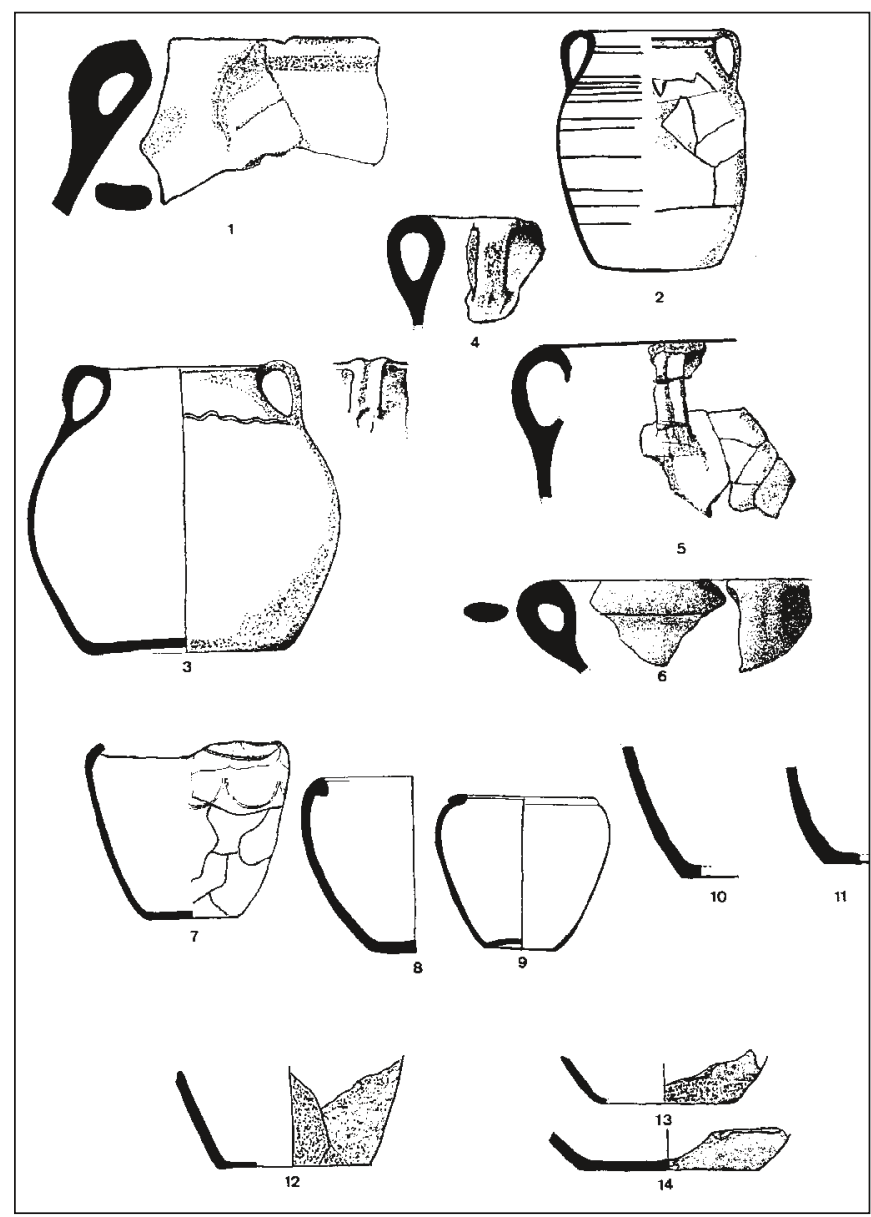

Fig. 8.- I.- Vasijas de cocina. Ollas con borde vuelto hacia afuera: 1.Casa Herrera (Mérida, Badajoz; según Caballero y Ulbert, 1976); 2.Camino de Los Afligidos (Alcalá de Henares, Madrid; según Fernández Galiano, 1976); 3-5.- Navalvillar (Colmenar Viejo, Madrid; según Caballero, 1989); Cuenco con dos asas: 6.- El Germo (Córdoba; según Ulbert). I.- Vasijas de cocina. Ollas con el borde vuelto hacia adentro: 7.- El Saucedo (Talavera la Nueva, Toledo); 8 y 9.- Vegas 1973; 10-11 Casa Herrera (Mérida, Badajoz; según Caballero y Ulbert, 1976); 12-14.- Necrópolis de El Cantosal (Coca, Segovia; según Lucas). 
estratos de época republicana de Pollentia pero también se encuentra en Tarragona durante el siglo I d.C.; pero será precisamente en el Bajo-Imperio cuando estas vasijas sean más numerosas (Vegas, 1973,17).

c) Cuencos con Pitorro.- Se deben incluir dentro del tipo 11 de Vegas y serie 26 de Gutierrez (Fig. 9, núms. 4 -10), Fig 10. num 1). Fueron empleados para la preparación de alimentos líquidos y funciones auxiliares (ordeño, maceración, fermentación, etc) (Gutiérrez, 1996,119). Estos cuencos con pico en forma de embudo existían en la vajilla romana de diversas épocas pero su uso se generalizará en el periodo Tardoimperial. La forma se ha documentado tanto en cerámica común como en Terra Sigillata Hispánica Tardía (forma 43) y en Terra Sigillata Gálica Tardía. Aunque a estos cuencos, como ya se ha expuesto líneas arriba, se les ha atribuído funciones destinadas a la manipulación de líquidos o a la producción de algún tipo de alimento como el garum, su elaboración en cerámica fina ha llevado a algunos investigadores a pensar que también sirvieran para el servicio de mesa (Gamo Parras, 1996, 369-370). La forma de estos cuencos Bajo Imperiales es hemiesférica, con borde, por lo general inclinado hacia adentro y pitorro bastante largo en forma de embudo colocado en la parte alta de la pared, por debajo del borde. Los estratos donde suelen aparecer se fechan en el siglo IV d.C. aunque no faltan los ejemplares constatados para el siglo V y VI d.C., como es este caso (Vegas, 1973, 39, fig.1.2)

d) Cuencos. Debido a la simplicidad técnica que presentan, constituyen uno de los grupos cerámicos que menos valoracio-

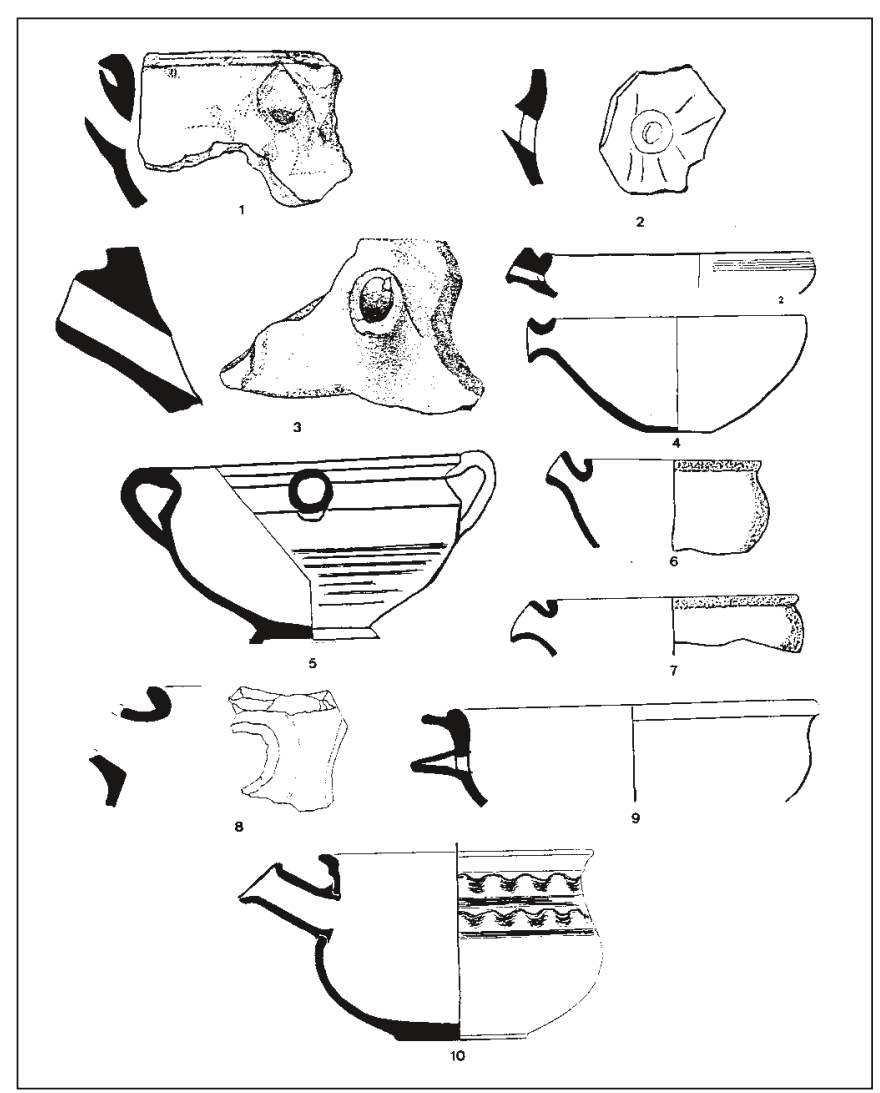

Fig. 9.- I.- Vasijas de cocina. Cuencos con pitorro: 1-3 El Saucedo (Talavera la Nueva, Toledo); 4 y 5 Tipo 11 de Vegas; 6-7 Portus Illicitanus (Santa Pola, Alicante; según Sánchez Fernández, 1983); 8.El Tolmo de Minateda (Hellín, Albacete; según Gamo Parras, 1996); 9.- El Real (Albacete; según Gamo Parras 1996) y 10.- Valencia (según Albiach y Soriano, 1991). nes de carácter cronológico y cultural pueden ofrecer, ya que la mayoría de los tipos se encuentran anclados en tradiciones formales y funcionales que arrancan desde los primeros momentos de la producción cerámica. Por tanto este tipo se puede encontrar presente desde momentos prerromanos hasta nuestros días. La pieza de El Saucedo, un cuenco de base plana, se puede incluir dentro de la forma 1A de Carrobles Santos y Rodríguez Montero. Como paralelos se pueden citar los hallados en el solar del Nuevo Mercado de Abastos (Poligono Industrial, Toledo); asi como los hallados en Cartuja, Conimbriga o Complutum (Carrobles Santos y Rodríguez Montero, 1988, 63-64).

\section{II.- Vasijas de Mesa}

a) Jarras de cuello moldurado y engrosado con una o dos asas.- Corresponde al tipo 42 de Vegas (Fig. 10, núm. 2). Se trata de jarras globulares o piriformes aunque predomina el segundo tipo con base rehundida, cuello largo y estrecho que puede estar adornado con acanaladuras salientes angulares o engrosamiento de la pared; líneas incisas horizontales y onduladas pueden alternarse con otros motivos. También el cuerpo puede presentar superficie ondulada. Estas jarras con molduras en el cuello se constatan desde épocas muy tempranas perdurando en época Tardo Imperial y visigoda (Vegas, 1973, 99). Ejemplos de estos tipos se recogen en la Fig. 10 nums. 4-5 y Fig. 11 núms. 1-8

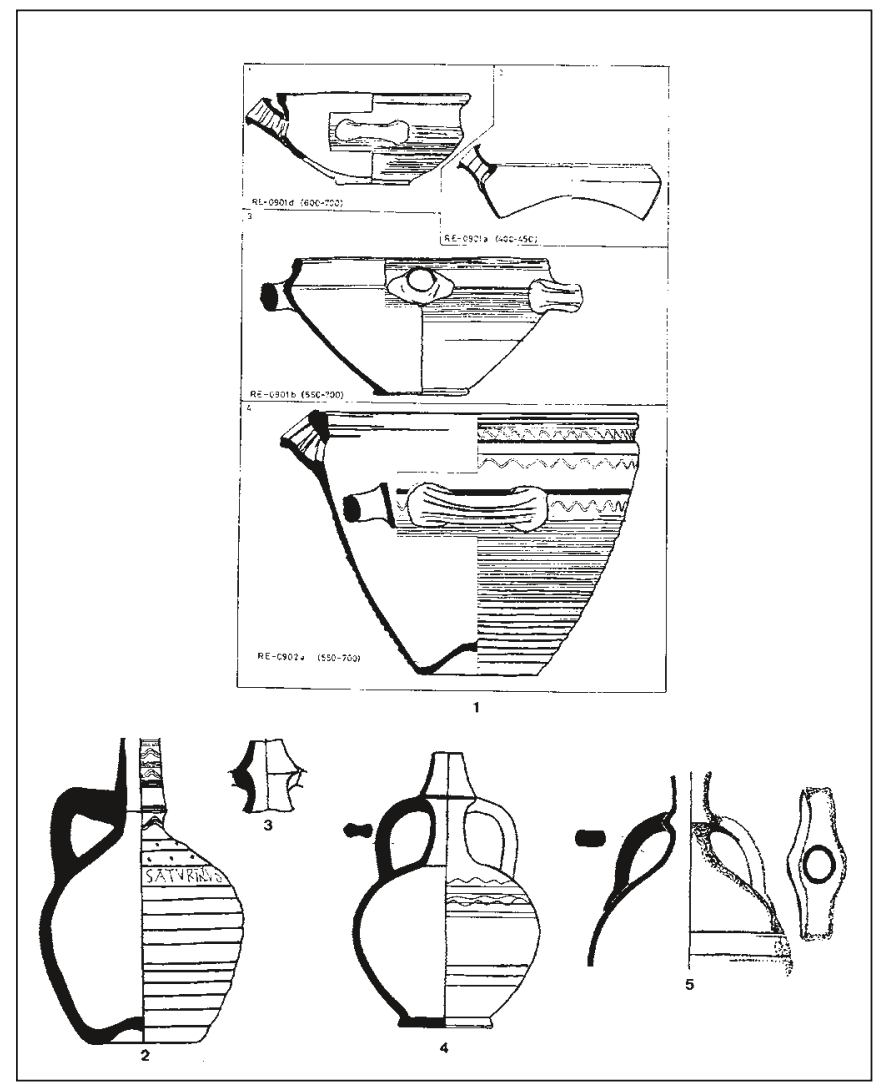

Fig.10.- I.- Vasijas de cocina. Cuencos con pitorro: 1.- Can Sorá (Ibiza, según Ramón, 1986); II.- Vasijas de Mesa. Jarras con cuello moldurado y engrosado con una o dos asas: 2.- Tipo 42 de Vegas, 1973; 3.- Alcalá de Henares (Madrid); 4.- Getafe (Madrid); 5.Navasangil (Ávila; según Larrén Izquierdo, 1989). 
La forma de época tardo imperial se caracteriza por presentar una base plana con una leve indicación del pie y un cuerpo ovoide que se estrecha muy velozmente por su parte superior para producir un cuello estrangulado antes de alcanzar el resalte o anilla de donde arrancan las dos asas. Por encima de este resalte se abre la boca cerrada (Abascal Palazón, 1986,195198 piezas 645 a 699). Diversos autores como Izquierdo, Caballero y Abascal Palazón consideran que estas piezas proceden de la Terra Sigillata Clara C y que llegarían a Hispania a través de las producciones Narbonenses (RIG.28). Sin embargo se produce el hecho de que esta forma es mayoritaria en la sigillata hispánica y rara vez se ejecuta en la región Narbonense (Caballero Zoreda, 1989,98). Abascal Palazón la define como forma 21 y además considera que es una imitación de la forma Palol-Cortés 14 de Terra Sigillata Hispánica Tardía (Abascal Plazón, 1986, 195-198).

b) Botellas de una o dos asas.- Se caracterizan por presentar una abertura de diámetro sensiblemente inferior al de las paredes del recipiente. Destinadas, como ya se expuso anteriormente, a la conservación y servicio del vino y otros líquidos. El cuello estrecho impedía efectivamemte el paso de alimentos o preparados de cierto volumen. A través de los ejemplares constatados en Casa Herrera (Badajoz); Ibahernando (Cáceres); Fuentespreadas (Zamora); San Miguel de Arroyo (Valladolid), San Pedro de Alcántara (Málaga) o Pollentia (Tarragona) se puede apreciar que son frecuentes las decoraciones a base de líneas horizontales incisas muy marcadas, tal y como se documentan en los ejemplares del yacimiento de Saucedo. Son

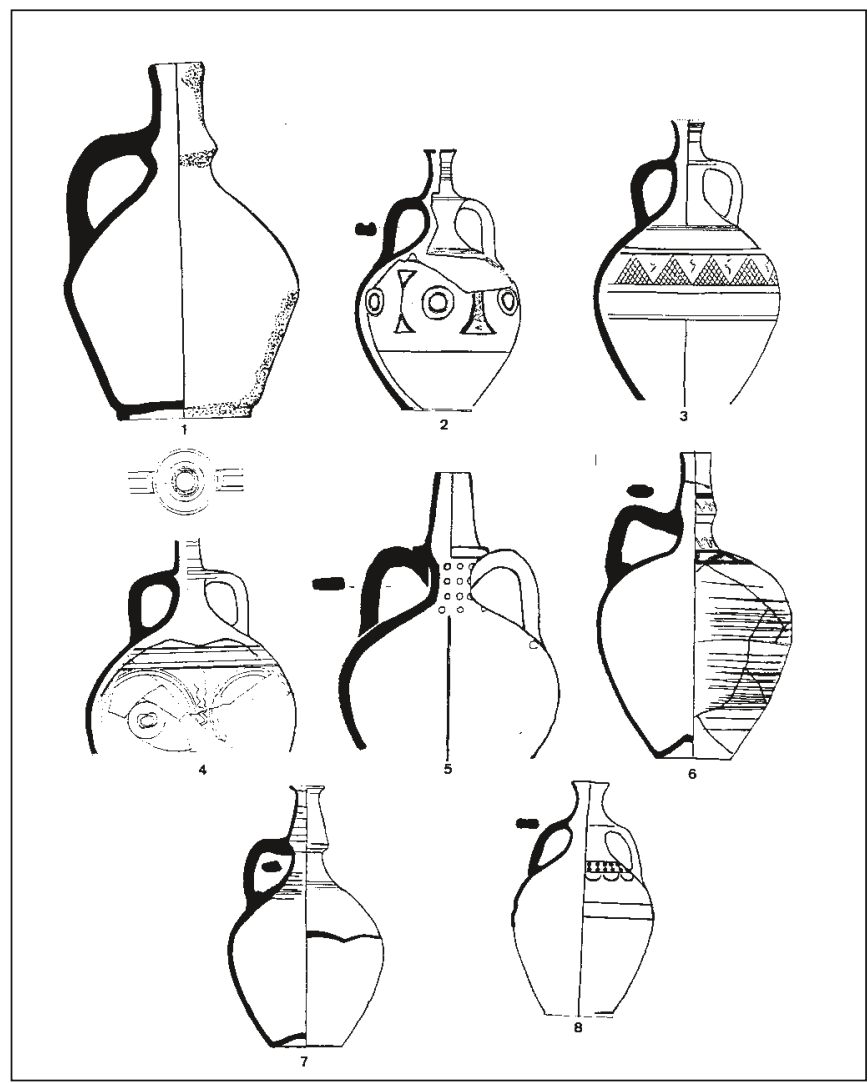

Fig. 11.- II.- Vasijas de Mesa. Jarras con cuello moldurado y engrosado con una o dos asas: 1.- Albalate de las Nogueras (Cuenca; según Fuentes Domínguez); 2-4 Segóbriga (Cuenca; según Abascal Palazón, 1986); 5.- Boatella (Valencia); 6-7.- Can Sorá (Ibiza; según Ramón 1986) y 8.- Procedencia desconocida. Depositada en el Museo Arqueológico Nacional de Madrid. muchos los ejemplares que se han constatado, no obstante cabe destacar los reflejados en la Fig 12, núms.3- 20

c) Jarras de boca trilobulada.- Corresponde al tipo 46 de Vegas. Forma 15 de Izquierdo Benito. Figs 13 y 14. Bajo este epígrafe se agrupan una serie de jarras cuya característica principal es el pico que forma una boca de tres lóbulos. Estas jarras derivan de los enocoes griegos y en época helenística el tipo ya es corriente en la cerámica común. El tipo es muy longevo y se puede encontrar con cronologías muy avanzadas sin apenas variaciones formales (Vegas, 1973, 109). Los ejemplares más tardíos han sido denominados en la mayoría de las ocasiones como "jarros visigodos"; según R. Lucas deberían denominarse de otra manera ya que, como se ha podido ver, no es una forma que pueda definirse como una creación de la propia cultura visigoda (Lucas, 1971, 395).

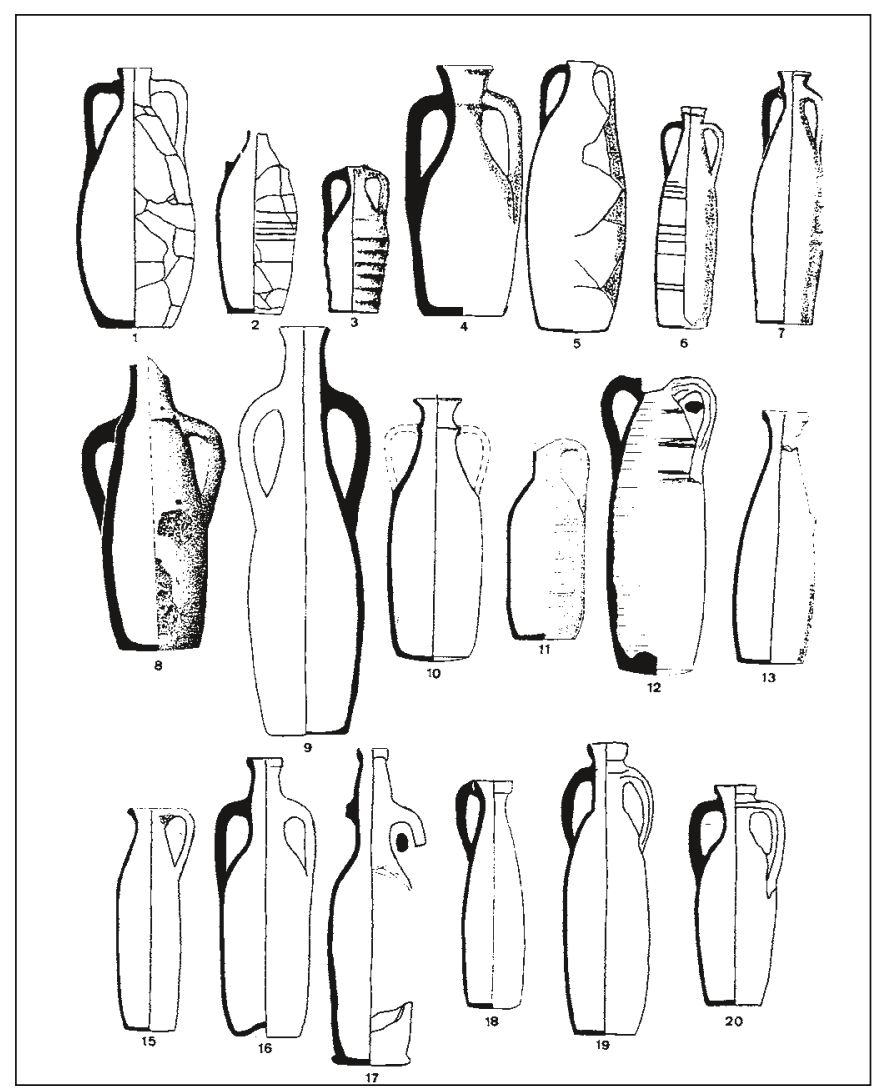

Fig. 12.- Vasijas de Mesa. Botellas de dos asas.- 1 y 2 El Saucedo (Talavera la Nueva, Toledo); 3.- Las Vegas de Pueblanueva (Toledo; según Klauppauf, 1978); 4.- Casa Herrera (Mérida, Badajoz; según Caballero Zoreda y Ulbert, 1976); 5-7.- Camino de Los Afligidos (Alcalá de Henares, silo I; según Fernández Galiano); 8.- Camino de Los Afligidos (Alcalá de Henares. Tumba n1 1; según Mendez y Rascón); 9.- Necrópolis de El Cerro de Las Losas (El Espartal, Madrid; según Alonso Sánchez, 1976); 10.- Necrópolis la Dehesilla (Almodovar del Pinar, Cuenca; según Almagro-Gorbea, 1970); 11.Vega del Mar (San Pedro de Alcántara, Málaga; según Hübener, 1965); 12.- El Tolmo de Minateda (Hellín, Albacete; según Gutierrez, 1996); 13-17.- Gerena (Sevilla; según Fernández Gómez et alii, 1987); 18.- Puerto Real (Cádiz; según Izquierdo Benito); 19 y 20 Procedencia desconocida. Depósito Museo Arqueológico Nacional de Madrid (según Izquierdo Benito). 


\section{3.-CONCLUSIONES.}

El estudio y análisis de los materiales cerámicos proporcionados por los trabajos realizados en la villa de El Saucedo que se presentan en este artículo, proporciona una serie de datos y conclusiones que ilustran la importancia y desarrollo de este establecimiento agropecuario durante las épocas romana y visigoda. Si bien, hay que insistir en el carácter parcial de este trabajo, configurado como una introduccion general al conocimiento histórico y arqueológico de esta villa; la visión proporcionada por el estudio de las fases de construcción y ocupación junto con los materiales cerámicos pertenecientes a cada una de ellas, muestra el gran arco cronológico (ss. I a VIII d.C.) durante el que este complejo rural estuvo habitado.

Por otro lado, la publicación de esta serie de ejemplares de diferentes producciones cerámicas, enriquece el conocimiento de que se disponía acerca de los períodos romano y visigodo en la Comunidad Autónoma de Castilla- La Mancha, y más especificamente en el área geográfica del Valle del Tajo dentro de la provincia de Toledo.

La presencia de materiales pertenecientes a todas las producciones cerámicas fabricadas durante estas cronologías, son un indicativo, no sólo de las distintas fases de ocupación y construcción de la villa, sino también de su desarrollo e integración dentro de los circuitos comerciales de la época, favore- cida por su estrategica situación entre las ciudades deAugustobriga y Caesarobriga y en las cercanías de la via de comunicación que enlazaba Augusta Emerita con Caesar Augusta, a través de Complutum .

Los ejemplos presentados correspondientes a las producciones de Terra Sigillata Gálica, permiten documentar la primera fase de ocupación y de construcción del complejo. En cuanto a las características propias de la cerámica, se confirma lo ya conocido para este área geográfica, en la que se aprecia la presencia de producciones fabricadas en su mayoría en los alfares de La Graufesenque, generalmente durante época flavia.

En cuanto a la Terra Sigillata Hispánica, los ejemplos proporcionados por esta villa abarcan la gran mayoría de las producciones y estilos decorativos propios de este tipo cerámico, en unas cronologías que no rebasan el s. II d. C. Por otro lado la procedencia de estas piezas indica las fuertes conexiones comerciales con la ciudad de Augusta Emerita, que actuaría como centro redistribuidor de este tipo de mercancías. Este hecho está documentado, al igual que en otros yacimientos castellano-manchegos por la presencia de producciones salidas tanto de los denominados talleres riojanos, como de los de Andújar, aunque las primeras sobrepasan ampliamente en cantidad a las segundas.

Como se ha indicado anteriormente los ejemplos pertenecientes a la Terra Sigillata Hispánica Tardía se configuran

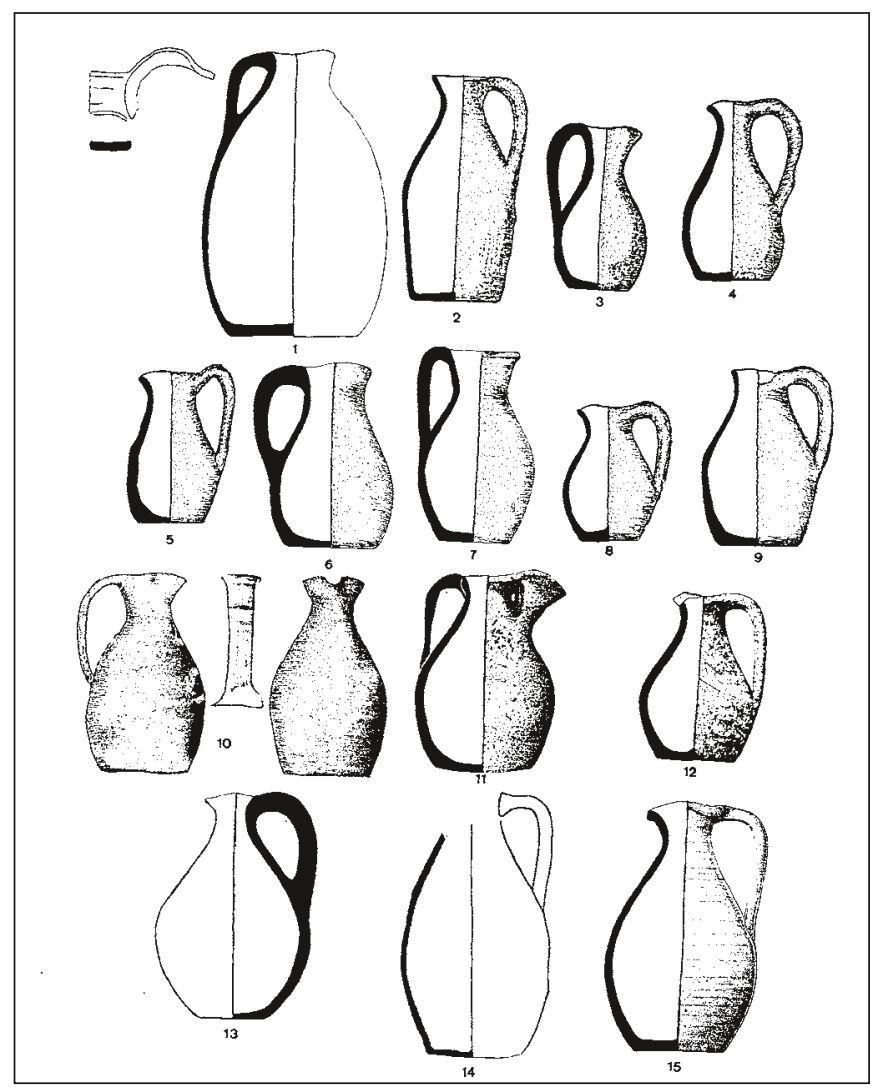

Fig. 13.- II.- Vasijas de Mesa. Jarras con boca trilobulada: 1.- Melque (San Martín de Montalbén, Toledo; según Caballero Zoreda; 2-10.Casa Herrera (Mérida, Badajoz; según Caballero y Ulbert, 1976); 11.Camino de Los Afligidos (Alcalá de Henares, Madrid. Tumba n1 1; según Fernández Galiano); 12.- El Cantosal (Coca, Segovia; según Lucas); 13.- Cerro de Las Losas (El Espartal, Madrid; según Alonso Sánchez, 1976); 14.- Casa Antoñete (Tarazona de la Mancha, Albacete; según Gamo Parras, 1996); 15.- Vega del Mar (San Pedro de Alcántara, Málaga; según Hübener, 1965).

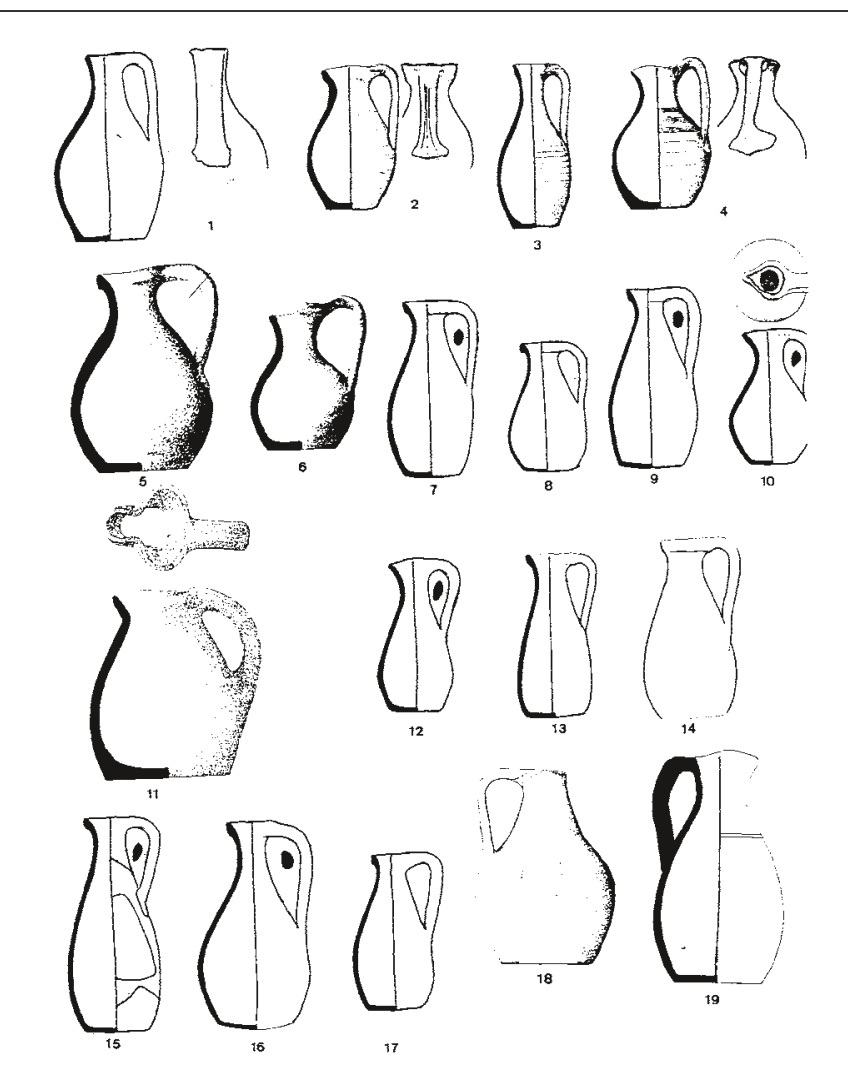

Fig. 14.- II.- Vasijas de Mesa. Jarras de boca trilobulada: 1-4 Vega del Mar (San Pedro de Alcántara, Málaga; según Hübener 1965); 5-6 Las Huertas (Pedrera, Sevilla); 7-10.- Gerena (Sevilla; según Fernández Gómez et alii, 1987); 11.- El Germo (Córdoba; según Caballero y Ulbert); 12-17 Gerena (Sevilla; según Fernández Gómez et alii, 1987); 18.- El Almendral (Granada) y 19.- Sin procedencia conocida. Depósito Museo Arqueológico Nacional de Madrid (según Izquierdo Benito). 
como los más numerosos y representativos de la principal fase de ocupación de la villa de El Saucedo. Una vez más las características tanto técnicas como decorativas presentan numerosos paralelos dentro del área geográfica del establecimiento, en especial, con ejemplares documentados en la antigua ciudad de Toletum.

Por último, la presencia de la cerámica común de época visigoda, con una buena representación de sus distintos tipos formales, pone de manifiesto la pervivencia y ocupación del lugar durante este periodo, conformándose este, al que, sin embargo, sucederá la fase de abandono definitivo.

Finalmente es necesario indicar que la presencia de estas diferentes producciones cerámicas, junto con la propia entidad arquitectónica del lugar, convierten este establecimiento rural romano en uno de los que más información puede proporcionar para conocer estos períodos históricos en la comarca de la actual Talavera de la Reina y en un sentido más amplio, dentro del área geográfica del Valle del Tajo.

\section{BIBLIOGRAFÍA}

ABASCAL PALAZÓN, J.M., 1984 “La cerámica pintada romana. Estudio de los mateales aparecidos en la Península Ibérica", Revista Arqueología, 38, pp. 43-52, Madrid.

ABASCAL PALAZÓN, J.M., 1986: La cerámica pintada romana de tradición indígena en la Península Ibérica. Centros de producción, comercio y tipologia, Madrid-Alicante.

AGUADO MOLINA, M., JIMÉNEZ CAÑIZOS,O., y RECIO MARTÍN, R.,e.p.: "Actividades económicas desarrolladas en la villa romana de El Saucedo (Talavera la Nueva, Toledo) a partir del estudio de los materiales de hierro", XXIV Congreso Nacional de Arqueología, octubre de 1997, Cartagena.

ALBIACH DELSCALS, R. y SORIANO SÁNCHEZ, R., 1991 "Estudio de una domus romana de Valentia y de los niveles que la amortizan", Saguntum, 24, pp. 75-95, Valencia.

ALMAGRO GORBEA, M., 1970 “Hallazgos de época visigoda en Almodovar del Pinar (Cuenca)", Trabajos de Prehistoria, 27, pp.311-323, Madrid.

ALONSO SÁNCHEZ, A. 1983: "Las estancias absidadas en las villae romanas de Extremadura", Norba, IV, 199-206, Cáceres.

ALONSO SÁNCHEZ, M0. A. 1976 “Necrópolis de El Cerro de Los Losas en el Espartal (Madrid)", Noticiario Arqueológico Hispano, 4, pp. 287-321, Madrid. ALONSO SÁNCHEZ, M0. A., 1994 "La necrópolis de El Cerro de las Losas", Boletín de la Asociación Española de Amigos de la Arqueología, 34, 37-38, Madrid.

ARGENTE OLIVER, J.L., 1979 “La villa tardorromana de Baños de Valdearados (Burgos)", Excavaciones Arqueológicas en España 100, Madrid.

ARRIBAS DOMÍNGUEZ, R., e.p.: "Hypocausta en la Lusitania romana. El Hypocausto de la villa de El Saucedo (Talavera la Nueva, Toledo)", XXIV Congreso Nacional de Arqueología, octubre de 1997, Cartagena.

BELTRÁN, 1990 Guía de la cerámica romana, Zaragoza.

BENDALA, M.; CASTELO, R. y ARRIBAS, R., e.p.: "La villa romana de El Saucedo (Talavera la Nueva, Toledo)", Madrider Mitteilungen, 39.

BLASCO, J.; ESCRIVÁ, V. y SORIANO, R., 1994 “Assaig de sintesi del panorama cerámic de la ciutat de Valencia a l'Antiquitat Tardana", III Reunió d' Arqueologia Cristiana Hispánica, 357-373, Barcelona (Maó, 1988)

BOURGEOIS, A. y MAYET, F. 1991: Fouilles de Belo VI: Les Sigillées. Madrid.

CABALLERO ZOREDA, L., 1980: “La iglesia y el monasterio visigodo de Santa María de Melque (Toledo). Arqueología y Arquitectura. San Pedro de la Mata (Toledo) y Santa Comba de Bande", Excavaciones Arqueológicas en España, 109, Madrid.

CABALLERO ZOREDA, L. 1989 “Cerámicas de época visigoda y postvisigoda de las provincias de Cáceres, Madrid y Segovia", Boletín Arqueología Medieval, 3, 75-107, Madrid.

CABALLERO ZOREDA, L. Y ULBERT, TH.1976, “La basílica paleocristiana de Casa Herrera en las cercanías de Mérida (Badajoz)", Excavaciones arqueológicas en España, 89, Madrid.

CARROBLES SANTOS, J. y RODRIGUEZ MONTERO, S., 1988. Memoria de las excavaciones de urgencia del solar del Nuevo Mercado de Abastos (Polígono Industrial, Toledo). Introducción al estudio de la ciudad de Toledo (s. IV d.C.), Diputación de Toledo.

CARROCERA FERNÁNDEZ, E y REQUEJO PAGÉS, 1989 "Producciones cerámicas tardías en Castros y villas asturianas", Boletín de Arqueología Medieval, 3, pp. 21-30, Madrid.
CASTELO RUANO, R. et alii, e.p.: “Aproximación a la cronología y desarrollo de la villa de El Saucedo (Talavera la Nueva, Toledo) a través de las estructuras arquitectónicas y los hallazgos monetarios" II Congreso de arqueología Peninsular, 1996, Zamora.

CASTELO RUANO, R. et alii, 1997: “La villa romana de El Saucedo (Talavera la Nueva, Toledo): construcciones termales y recientes hallazgos monetarios", Boletín de la Asociación Española de Amigos de la Arqueología, 37, pp. 63-98, Madrid.

CASTELO RUANO, R. et alii, e.p.: "Los pavimentos musivarios de la villa romana de El Saucedo (Talavera la Nueva, Toledo)", XXIV Congreso Nacional de Arqueología, octubre de 1997, Cartagena.

CERRILlO MARTÍN DE CACERES, E., 1981: “Las ermitas de Portera y SantaOlalla. Aproximación al estudio de la cabeceras rectangulares del siglo VII", Zephyrus, XXXII-XXXIII, pp. 233-243, Salamanca.

CERRILLO MARTÍN DE CÁCERES, E., 1983 La basílica de época visigoda de Ibahernando, Cáceres.

COLMENAREJO GARCÍA, F., 1986 “El yacimiento arqueológico de Fuente del Moro", Actas del I Congreso de Arqueología Medieval Española, pp. 221-239 (1985, Huesca).

DELGADO, F; MAYET, F.; MOUTINHO DE ALARCAO, A.; 1975: Fouilles de Conimbriga IV: Les sigilées.

ENCINAS, M y GARCÍA CARRILLO, A., 1992 “Aportaciones al c onocimiento de la transición del mundo romano medieval en Asturias: las cerámicas de Murias de Beloño y de Paraxuga", III Congreso de Arqueología Medieval Española, 131-139 (Oviedo, 1989).

FERNÁNDEZ GALIANO, D., 1976 “Excavaciones en la necrópolis visigoda del Camino de Los Afligidos (Alcalá de Henares). 1975”, Noticiario Arqueológico Hispánico, 4, 5-90, Madrid.

FERNÁNDEZ GALIANO, D., 1992: “Las villas hispanorromanas”, Cuadernos de Arte Español, 26, Historia 16, Madrid.

FERNÁNDEZ GÓMEZ ET ALII, 1984 “", Noticairio Arqueológico Hispénico, 19, Madrid.

FERNÁNDEZ GÓMEZ ET ALII, 1987 “La basílica y necrópolis paleocristiana de Gerena (Sevilla)", Noticiario Arqueológico Hispánico, 29, Madrid.

FITA, F., 1882: AInscripciones romanas de la ciudad y partido de Talavera, provincia de Toledo, Boletín de la Real Academia de la Historia, Tomo II, pp. 248 y SS.

FUENTES DOMíNGUEZ, A., 1995: “Extremadura en la Tardía Antigüedad", Extremadura Arqueológica, IV, Arqueología en Extremadura: 10 años de descubrimientos, pp. 217-237.

FUENTES DOMÍNGUEZ, A., 1989 La necrópolis Tardorromana de Albalate de Las Nogueras (Cuenca) y el problema de las denominadas "necrópolis de El Duero", Cuenca.

GAMO PARRAS, B., 1996 La antigúedad tardía en laprovincia de Albacete. Memoria de Licenciatura. Universidad Autónoma de Madrid. Departamento de Prehistoria y Arqueología (Inédita).

GARCÍA Y BELLIDO, A., 1970 “Estudios sobre la Legio VII Gemina y su campamento en León", Legio VII Gemina, pp. 571-594, León.

GARABITO GÓMEZ, T. (1978): “Los alfares romanos riojanos: produccion y comercialización", Bibliotheca Praehistorica Hispana, vol. XVI.

GARABITO, T. ET ALLI (1985): "Los alfares romanos riojanos y la comercialización de sus productos en la región de Castilla-La Mancha", Actas de las I Jornadas de Historia de Castilla-La Mancha, Tomo IV, pp. 131-140, Ciudad Real..

GIMÉNEZ REYNA, S., 1947, “El cementerio paelo-cristiano de Cartama (Málaga)”, Actas y Memorias de la Sociedad Españolade Antropología, Etnografía y Prehistoria. Homenaje a J. Martínez Santa Olalla, XXII, 1-4, pp. 37-43.

GUARDIA PONS, M., 1992 Los mosaicos de la Antigüedad Tardía en Hispania. Estudios de Iconografía, Barcelona.

GURT ESPARRAGUERA, J., 1995: “Topografía cristiana de la Lusitania. Testimonios arqueológicos", Los últimos romanos en Lusitania. Cuadernos Emaritenses. Museo Nacional de Arte Romano, 10, pp. 75-95, Mérida.

GURT ESPARRAGUERA J. et alii, 1994: "Topografía de la antigüedad tardía. Reflexiones para una propuesta de trabajo".Antiquité tardive, II, pp. 161-180, París. GUTIERREZ, S., 1996 La Cora de Tudmir de la Antigüedad Tardía al mundo islámico, Collection de La Casa Velázquez, 57 (Madrid-Alicante).

HAUSCHILD, Th., 1968: “La iglesia martirial de Marialba (León)”, Boletín de la Real Academia de la Historia, CLXII, pp. 243-249, Madrid.

HAUSCHILD, Th., 1970 “Die Märtyrer-Kirche von Marialba bei León”, Legio VII Gemina, pp. 513-521, León.

HERMET, 1934:La Graufesenque., Paris.

HÜBENER, W., 1965 “Zur Chronologischen Gliederung des Gräberfeldes von San Pedro de Alcántara, Vega del Mar (Prov. Málaga)", Madrider Mitteilungen, 6, pp. 195-214.

IZQUIERDO BENITO, R., 1977 “Cerámica de necrópolis de épocas visigoda del MAN" Revista de Archivos, Bibliotecas y Museos, LXXX,3, pp. 569-611, Madrid.

IZQUIERDO BENITO, R., 1977 “Ensayo de una sistematización tipológica de 
la cerámica de necrópolis de época visigoda", Revista de Archivos, Bibliotecas y Museos, LXXX, 4, pp. 837-865, Madrid.

JUAN NAVARRO, E Y CENTECELLES IZQUIERDO, F.X., 1986 “El yacimiento de época visigoda del Plá de Nadal (Riba-Bajo de Turia, Camp de Turia, Valencia)", Actas del I Congreso Nacional de arqueología medieval espa'ñola, tomoII, pp. 25-40 (Huesca, 1985).

JUAN TOVAR, L.C., MORALEDA OLIVARES, A., y RODRÍGUEZ SANTAMARÍA, A. , 1983. “Elementos de alfar de sigillata hispánica en Talavera de la Reina (Toledo). Alfares de sigillata en la cuenca del Tajo". Boletín del Museo Arqueológico Nacional, I, 2, pp. 165-175.

JUAN TOVAR, L.C., 1988. "Nuevos datos sobre el alfar de sigillata de Talavera de la Reina (Toledo)", Actas del I Congreso de Historia de Castilla-La Mancha, vol. IV, Toledo, pp. 141-144.

KLAUPPAUF, L. , 1978 "Zur Keramik aus dem Mausoleum von Las Vegas de Puebla Nueva (Prov. Toledo)", Madrider Mitteilungen, 19, 340-378.

LARRÉN IZQUIERDO, H., 1989 “Materiales cerámicos de la Cabeza Navasangil (Ávila)", Boletín de Arqueología Medieval, 3, pp. 31-51, Madrid.

LUCAS DE VIÑAS, R., 1971, "El Cantosal, Coca (Segovia)", Noticiario Arqueológico Hispánico, XVI.

MAYET, F. 1975: Les céramiques a parois fines dans la Péninsule Ibérique, Paris.

MAYET, F, 1984: Les céramiques sigillées hispaniques, Paris.

MENDEZ MADARIAGA, A. Y RASCÓN MARQUÉS, S., 1989 “Los visigodos en Alcalá de Henares", Cuadernos del Juncal, 1, Alcalá de Henares.

MEZQUIRIZ, M.A. 1961: Terra Sigillata Hispánica, Valencia

PALOL. P., 1967 "En torno a la iconografía de los mosaicos cristianos de las Islas Baleares", Actas de la I Reunión Nacional de Arqueología Paleocristiana, pp. 131-149, (Vitoria, 1996), Vitoria.

PALOL, P., 1969 "La necrópolis de San Miguel de Arroyo y los broches hispanorromanos del siglo IV" Boletín del Seminario de Arte y Arqueología, XXXIVXXXV, pp.93 y ss., Valladolid.

PÉREZ CONZÁLEZ, C. y JUAN TOVAR, L.C., 1984: “Notas para el estudio de la Terra Sigillata Gálica en la provincia de Toledo", Actas del I Congreso de Historia de Castilla-La Mancha. Tomo IV: Romanos y Visigodos, pp. 145-150, Ciudad Real, 1985.

PÉREZ VILlANUEVA, J.; TOVAR, A Y SUPPIOT, J., 1932-1933 “Avence de estudio sobre la necropoli visigoda de Piña Esgueva", Boletín del Seminario de Arte y Arqueología, pp. 253-267, Valladolid.
POSAC MON, C. y PUERTAS TRICAS, R., 1989 La basílica paleocristiana de Vega del Mar (San Pedro de Alcántara, Marbella), Málaga.

QUERO CASTRO, S. Y MARTÍN FLORES, A., 1987 “La cerámica hispanovisigoda de Perales", II Congreso Arqueología Medieval Española, pp. 373-378 (Madrid 1987)

RAMALLO ASENSIO, S.F., 1990: "Talleres y escudos musivarios en la Península Ibérica", Mosaicos romanos. Estudios de Iconografía. Actas del Homenaje in Memoriam Alberto Balil Iliana, pp. 135-180, Alcalá de Henares.

RAMÓN, J. 1986 El Baix Imperi i l' epoca Bizantina a les Illes Ptiüses, Barcelona.

RAMOS SÁINZ, M.L., 1992: “Una piscina bautismal de planta cruciforme descubierta en la villa romana de El Saucedo (Talavera de la Reina, Toledo)", III Reunió d'Arqueologia cristiana Hispánica, pp. 105-110, (Maó, 1988).

RAMOS SÁINZ, M.L. y CASTELO RUANO, R., 1992: “Excavaciones en la villa romana de Saucedo (Talavera de la Reina, Toledo). Últimos avances en relación al hallazgo de una basílica paleocristiana", Actas Primeras Jornadas de Arqueología de Talavera de la Reina y sus tierras, (Talavera de la Reina, 1990), pp. 115-137, Toledo.

RAMOS SÁINZ, M.L. y DURÁN CABELLO, R.M., 1988: “La villa romana de Saucedo (Talavera de la Reina, Toledo). Aportaciones a su estudio en relación a la implantación de villas romanas en la Vega del Tajo", I Congreso de Historia de Castilla-La Mancha, IV, pp. 237-243, (Ciudad Real, 1985).

SOTOMAYOR, M. (1977): Marcas y estilos de la sigillata decorada de Andújar., Jaén.

SÁNCHEZ FERNÁNDEZ, M0.J., 1983 “Cerámica común romana del Portus Illicitanus", Lucentum, II, pp. 285-317, Alicante.

SERRANO RAMOS, E. y ALIJO HIDALGO, F., 1992 “Una necrópolis de época hispano-visigoda en las eras de Peñarrubia (Málaga)", Actas del III Congreso de Arqueología Medieval Española, t.II. Comunicaciones, 110-120 (Oviedo, 1989) TORRECILLA AZNAR, A., e.p.: "Materiales de construcción en las termas de la Hispania romana. A propósito de los materiales hallados en la villa de "El Saucedo" (Talavera la Nueva, Toledo)", XXIV Congreso Nacional de Arqueología, octubre 1997, Cartagena.

ULBERT, TH., 1968 "El Germo Kirche und profanbau as dem Frühen 7 Jahrhundert",Madrider Mitteilungen, 9, 329 y ss.

VEGAS, M. 1973, Cerámica común romana del Mediterráneo occidental, Barcelona. 